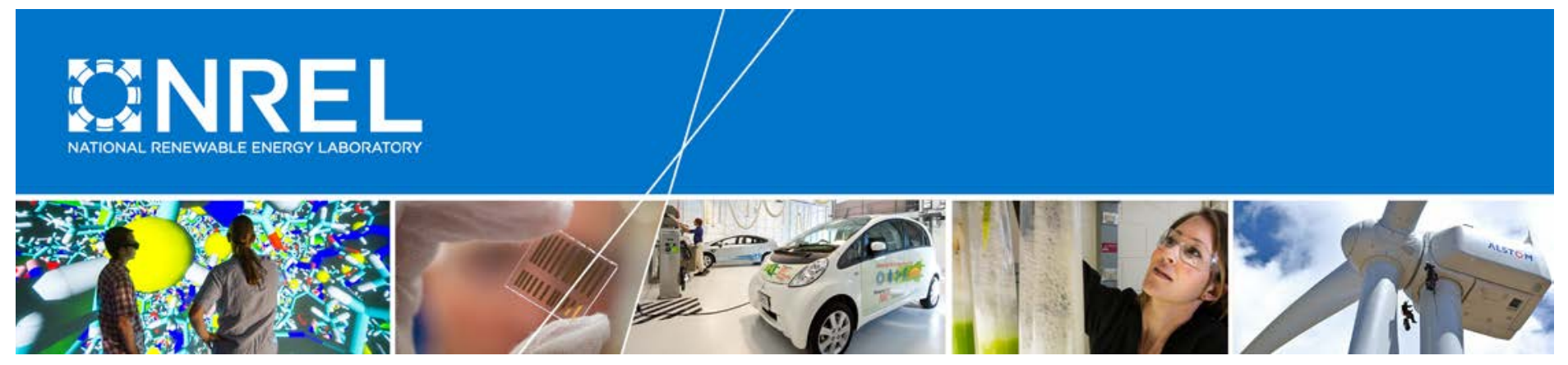

\title{
Quantifying Interannual Variability for Photovoltaic Systems in PVWatts
}

David Severin Ryberg, Janine Freeman, and Nate Blair

National Renewable Energy Laboratory

NREL is a national laboratory of the U.S. Department of Energy Office of Energy Efficiency \& Renewable Energy Operated by the Alliance for Sustainable Energy, LLC

This report is available at no cost from the National Renewable Energy Laboratory (NREL) at www.nrel.gov/publications.

Technical Report

NREL/TP-6A20-64880

October 2015

Contract No. DE-AC36-08GO28308 


\section{Quantifying Interannual Variability for Photovoltaic Systems in PVWatts}

David Severin Ryberg, Janine Freeman, and Nate Blair

National Renewable Energy Laboratory

Prepared under Task No. SS13.5030
NREL is a national laboratory of the U.S. Department of Energy Office of Energy Efficiency \& Renewable Energy Operated by the Alliance for Sustainable Energy, LLC

This report is available at no cost from the National Renewable Energy Laboratory (NREL) at www.nrel.gov/publications.
National Renewable Energy Laboratory 15013 Denver West Parkway Golden, CO 80401

303-275-3000 • www.nrel.gov
Technical Report

NREL/TP-6A20-64880

October 2015

Contract No. DE-AC36-08GO28308 


\title{
NOTICE
}

This report was prepared as an account of work sponsored by an agency of the United States government. Neither the United States government nor any agency thereof, nor any of their employees, makes any warranty, express or implied, or assumes any legal liability or responsibility for the accuracy, completeness, or usefulness of any information, apparatus, product, or process disclosed, or represents that its use would not infringe privately owned rights. Reference herein to any specific commercial product, process, or service by trade name, trademark, manufacturer, or otherwise does not necessarily constitute or imply its endorsement, recommendation, or favoring by the United States government or any agency thereof. The views and opinions of authors expressed herein do not necessarily state or reflect those of the United States government or any agency thereof.

This report is available at no cost from the National Renewable Energy Laboratory (NREL) at www.nrel.gov/publications.

Available electronically at SciTech Connect http:/www.osti.gov/scitech

Available for a processing fee to U.S. Department of Energy and its contractors, in paper, from:

\author{
U.S. Department of Energy \\ Office of Scientific and Technical Information \\ P.O. Box 62 \\ Oak Ridge, TN 37831-0062 \\ OSTI http://www.osti.gov \\ Phone: 865.576.8401 \\ Fax: 865.576.5728 \\ Email: reports@osti.gov
}

Available for sale to the public, in paper, from:

\author{
U.S. Department of Commerce \\ National Technical Information Service \\ 5301 Shawnee Road \\ Alexandria, VA 22312 \\ NTIS http://www.ntis.gov \\ Phone: 800.553 .6847 or 703.605 .6000 \\ Fax: 703.605.6900 \\ Email: orders@ntis.gov
}




\section{List of Acronyms}

$\mathrm{kWh}$

NREL

PV

SAM

TMY

NSRDB

SDK kilowatt-hour

National Renewable Energy Laboratory

photovoltaic

System Advisor Model

typical meteorological year

National Solar Radiation Database

software development kit 


\section{Introduction}

The National Renewable Energy Laboratory's (NREL's) PVWatts is a simple tool used by industry and individuals alike to estimate the amount of energy a photovoltaic (PV) system will produce throughout the course of a typical year. PVWatts has previously been shown to be able to reasonably represent an operating system's output when provided with concurrent weather data [1]. For estimating typical system production, PVWatts uses weather data from typical meteorological year (TMY) data sets which are available on the NREL website. The TMY files represent a statistically "typical" year which by definition excludes anomalous weather patterns and as a result may not provide sufficient quantification of project risk to the financial community. In response, this report quantifies the interannual variability associated with typical year energy production estimates in order to improve the understanding of weather risk associated with these projects.

To begin to understand the interannual variability of a PV project, we simulated two archetypal PV system designs that are common in the PV industry in PVWatts using the NSRDB's 19611990 historical data set. This data set contains measured hourly weather data and spans the thirty years from 1961 to 1990 for 239 locations in the United States. This historical data set was used to compose the TMY2 data set. Using the results of these simulations we computed several statistical metrics which may be of interest to the financial community and normalized the results with respect to the TMY energy prediction at each location. This report briefly describes the simulation process used and the statistical methodology employed for this project, but otherwise focuses mainly on a sample of our results. A short discussion of the results is also provided. This quantification of the interannual variability of PV systems could provide a starting point for variability considerations in future PV system designs and investigations. 


\section{Methodology}

\section{Simulation}

We used the 1961-1990 NSRDB historical data set which was the basis for the NSRDB's TMY2 data set. This historical data set is comprised of hourly measured weather data at each of the 239 TMY2 locations for each of the years from 1961 and 1990, inclusive. This data set was chosen because it has the longest period of record of the various publicly available measured data sets to date. Moreover this data set is freely available to those who may wish to recreate or expand upon the study presented in this report.

Simulations were performed using the PVWatts within NREL's System Advisor Model (SAM) version 2015.06.30 which is a desktop application that performs both physical and financial simulations of PV systems as well as of other renewable technologies (https://sam.nrel.gov). Within SAM we modeled two common PV system configurations, the inputs parameters of which are shown in Table 1. The only difference between the two simulations is in the variable 'array_type' (see Table 1), where a value of 0 corresponds to a fixed-tilt system and 2 corresponds to a one-axis-tracking system without back tracking. From this point forward the first simulation will be referred to as the 'fixed simulation' while the second will be referred to as the 'tracking simulation'.

Table 1. Input Parameters for SAM

\begin{tabular}{|llll|} 
Variable & Unit & Fixed & Tracking \\
\hline system_capacity & $\mathrm{kW}(\mathrm{dc})$ & 4 & 4 \\
\hline module_type & - & 0 & 0 \\
\hline dc_sc_ratio & - & 1.1 & 1.1 \\
\hline inv_eff & $\%$ & 96 & 96 \\
\hline losses & $\%$ & 14.1 & 14.1 \\
\hline array_type & - & 0 & 2 \\
\hline tilt & degrees & 20 & 20 \\
\hline azimuth & degrees & 180 & 180 \\
\hline gcr & - & 0.4 & 0.4 \\
\hline
\end{tabular}

By using the Python wrapper available in SAM's SDK (version 2015.06.30), we performed a simulation for both system designs, at each location, and for each of the 30 years between 1961 and 1990. In total we conducted slightly over 14,000 individual simulations and in each case recorded the resulting annual energy estimation from each simulation for later use in our analyses. 


\section{Analysis}

After performing each simulation and gathering the estimated annual energy production in each case, several statistical measures were calculated to help quantify the risk of a PV project. Most prominent among these statistical measures were the P90, P50, and P10 probabilities of exceedance. ${ }^{1}$ The P90 defines the point separating the top $90 \%$ of observed annual energy values from the lower $10 \%$. That is to say, future annual energy values are expected to have a $90 \%$ chance of exceeding the P90 value. Similarly the P50 defines the point where these future values will have a $50 \%$ probability of exceedance. These probabilities are often computed assuming a normal distribution, in which case the P50 is equal to the mean, and the P90 and P10 can be calculated using the standard deviation. However, assuming a normal distribution for solar resource data may not always be accurate, in which case calculated parameters obtained from a normal analysis will be of dubious value. Normal analysis on solar data may still be useful if appropriately interpreted; for example, the mean is still simply the average of all observed values and the standard deviation provides insight into the "spread" of the observed values, regardless of distribution type. For this study we calculated, from the 30 values at each location and system design, the average and standard deviation from a normal analysis, as well as empirically defined P90, P50, and P10 exceedance values.

The specific method used in this work to empirically determine the P90, P50 and P10 exceedance values is illustrated in Fig. 1. This is the same method as that discussed in [2] and is as follows:

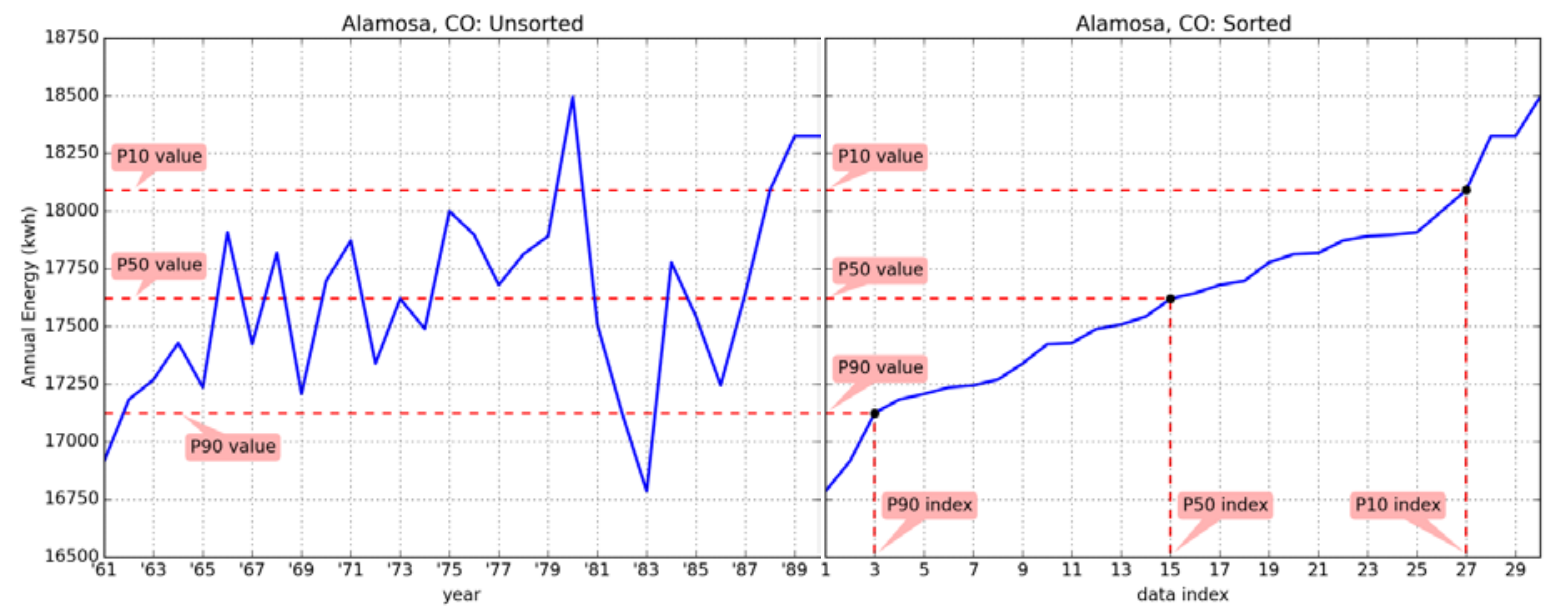

Figure 1. Empirically defined P90, P50, and P10 values using an example data set

The plot on the left shows the raw observed data set while the plot on the right shows the same data set after it has been sorted. In both cases the $y$-axis has been shifted to only include the data range. Because there are 30 values in this set, the indexes associated with the P90, P50 and P10 values are the whole numbers 3, 15, and 27 . Therefore, the empirical P90, P50, and P10 exceedance values are simply the values of the sorted data set at these indexes: 17,123 kilowatt-hours (kWh), 17,620 kWh, and 18,113 kWh.

\footnotetext{
${ }^{1}$ These P90, P50, and P10 values do not represent the overall energy uncertainty; rather, they represent this sample
} of data, where the only uncertainty is the interannual weather variability. 
1. Order the data in an ascending manner.

2. Find the index which corresponds to the desired $x$-value (where an index of 1 corresponds to the first value in the ordered data set and $N$ corresponds to the total number of values):

$$
\begin{aligned}
& P 90 \text { index }=N * 0.10 \\
& P 50 \text { index }=N * 0.50 \\
& P 10 \text { index }=N * 0.90
\end{aligned}
$$

3. Find the corresponding exceedance y-value in the data set.

- For each case, if the index is a whole number on the x-axis, then the corresponding exceedance value is simply the $y$-value of the ordered data set at that index

- If the index is not a whole number then the corresponding exceedance value is equal to a linear approximation between the two adjacent values using:

$$
\text { exceedance value }=\left(\mathrm{d}_{\mathrm{H}}-d_{L}\right) *(i-L)+d_{L}
$$

where $\mathrm{H}$ and $\mathrm{L}$ are the higher and lower index values adjacent to the calculated index, $\mathrm{i}$, and $\mathrm{d}_{\mathrm{H}}$ and $\mathrm{d}_{\mathrm{L}}$ are the $\mathrm{H}^{\text {th }}$ and $\mathrm{L}^{\text {th }}$ data values within the ordered data set.

After determining the average, the standard deviation, and the P90, P50, and P10 exceedance values for the annual energy production estimates, it was also determined that the calculated values would need to be normalized by some comparable value to make meaningful comparisons between locations whose typical weather patterns are vastly different from each other. We felt that the most useful parameter for this purpose would be the annual energy predicted by a SAM simulation using the TMY2 weather file for each location. Normalizations are calculated either as a percentage of the TMY value according to the following equation:

$$
\text { normalized value }=100 \% * \frac{\text { value }}{\text { TMY }}
$$

or else as a percent difference of the TMY value according to:

$$
\text { normalized value }=100 \% * \frac{\text { value }-T M Y}{T M Y}
$$

TMY files are constructed by conjoining entire months from the underlying historical weather files to form one complete year. For each month in the final TMY file, the most 'typical' month is chosen from the historical weather files based on the method described in [2]. TMY files do not, strictly speaking, represent the average weather patterns for each hour during the year. Nevertheless, because TMY files are intended to represent typical weather patterns for a single year the result of the simulations with these files were, as expected, generally very similar to the average annual energy production as well as to the P50 values for each location. 


\section{Sample Results and Discussion}

We produced a collection of histogram plots, displaying the distribution of energy productions for a given location and system design over the 30-year period. In this process, we produced far too many plots to include in this report; however, results for all locations will all be made available on the PVWatts web tool page (http://pvwatts.nrel.gov/). Fig. 2 displays a sample of the histogram plots that were produced during this analysis for two locations: Alamosa, Colorado and Olympia, Washington. In addition to portraying the distribution at each location, the plots shown in this figure also indicate the calculated mean, P90, and P10 values. The P50 value was generally very close to the average and so is not indicated in this figure.
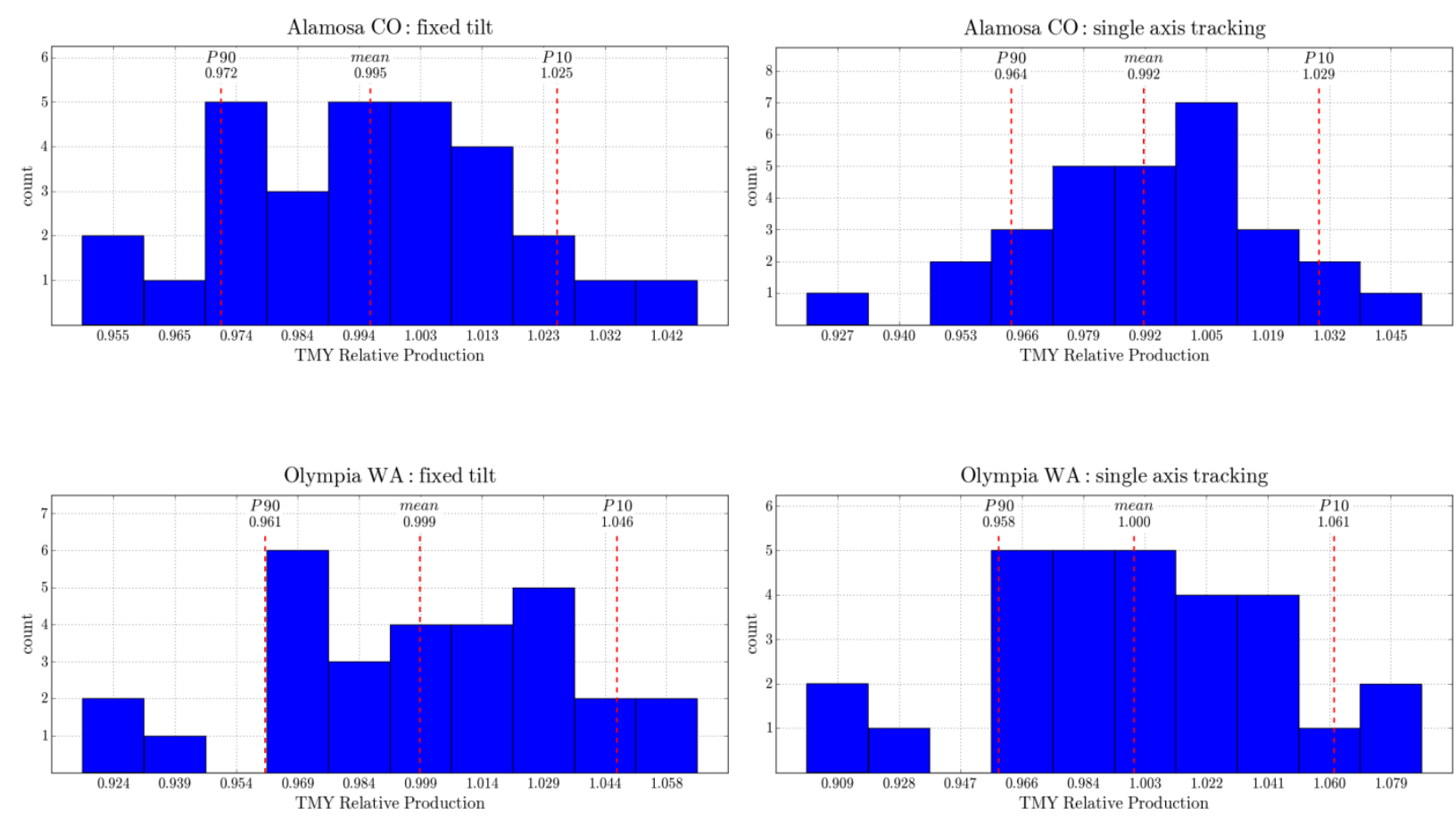

Figure 2. Sample histogram plots resulting from our analysis

The top two plots correspond to a fixed-tilt PV array and a one-axis tracking systems, respectively, in Alamosa, Colorado. The bottom two plots correspond to a fixed-tilt and a one-axis tracking system, respectively, except located in Olympia, Washington.

Production values are reported as a percentage of the TMY estimation value. Additionally the mean, P90 and P10 production values for each distribution are indicated.

For comparison, aggregated plots projected onto a map of the United States were also produced and a sample of these is shown in Fig. 3 and Fig. 4. Fig. 3 depicts normalized P90 values for each system design and as such may be the most useful for quantifying project risk with respect to interannual variability. From these maps it can be seen that the lowest P90 energy value, across both system designs, was 9.2\% less than the associated TMY energy prediction while the average P90 energy value was 4.8\% less than the TMY energy prediction. Again, these P90 values do not represent the overall energy uncertainty; rather, they represent this sample of data, 
where the only uncertainty is the interannual weather variability. Additionally, the fixed-tilt systems are shown to have slightly higher normalized P90 energy values than the one-axis tracking systems at the corresponding location indicating that fixed-tilt systems experience slightly less variation.
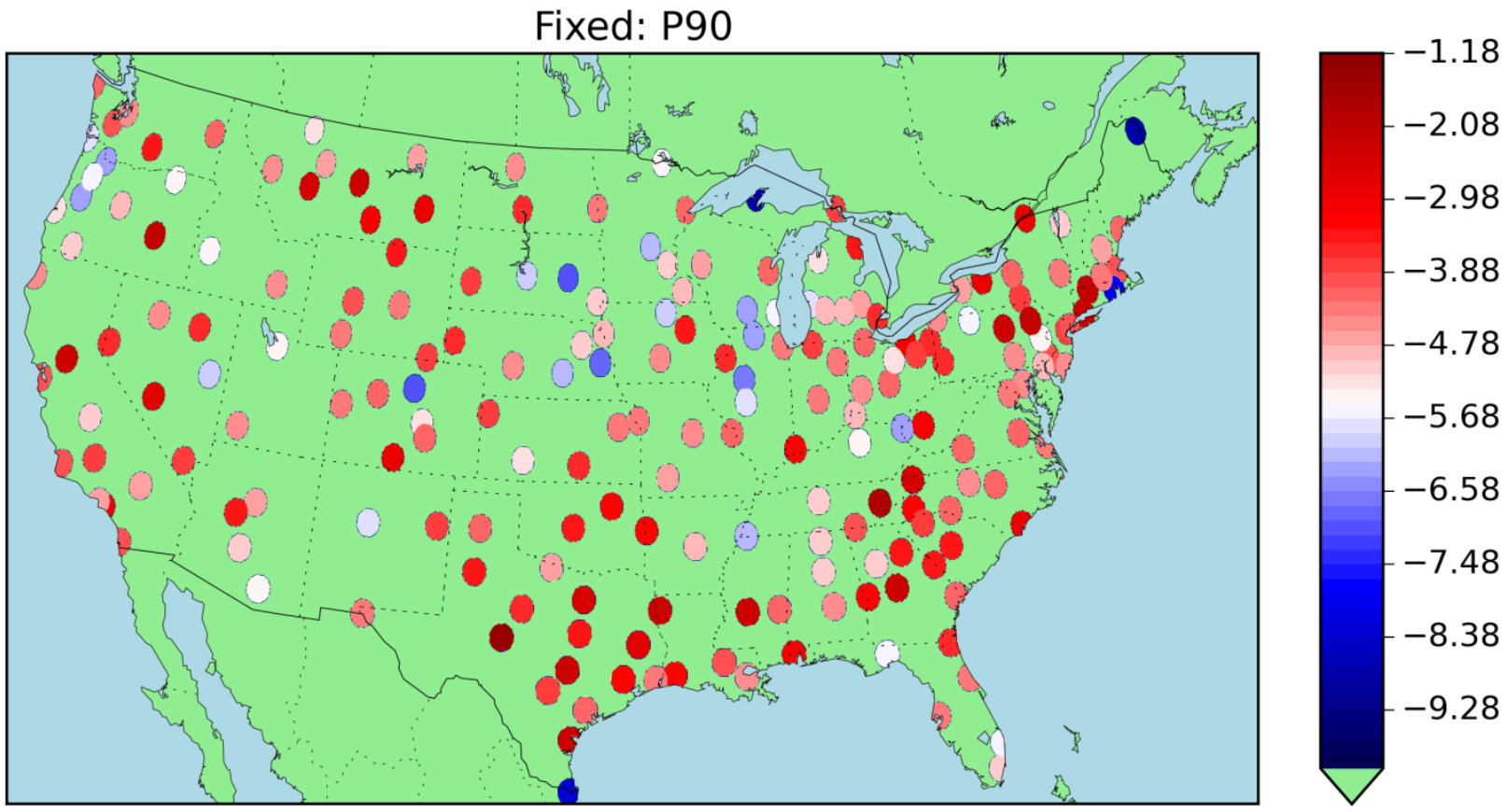

\section{Tracking: P90}

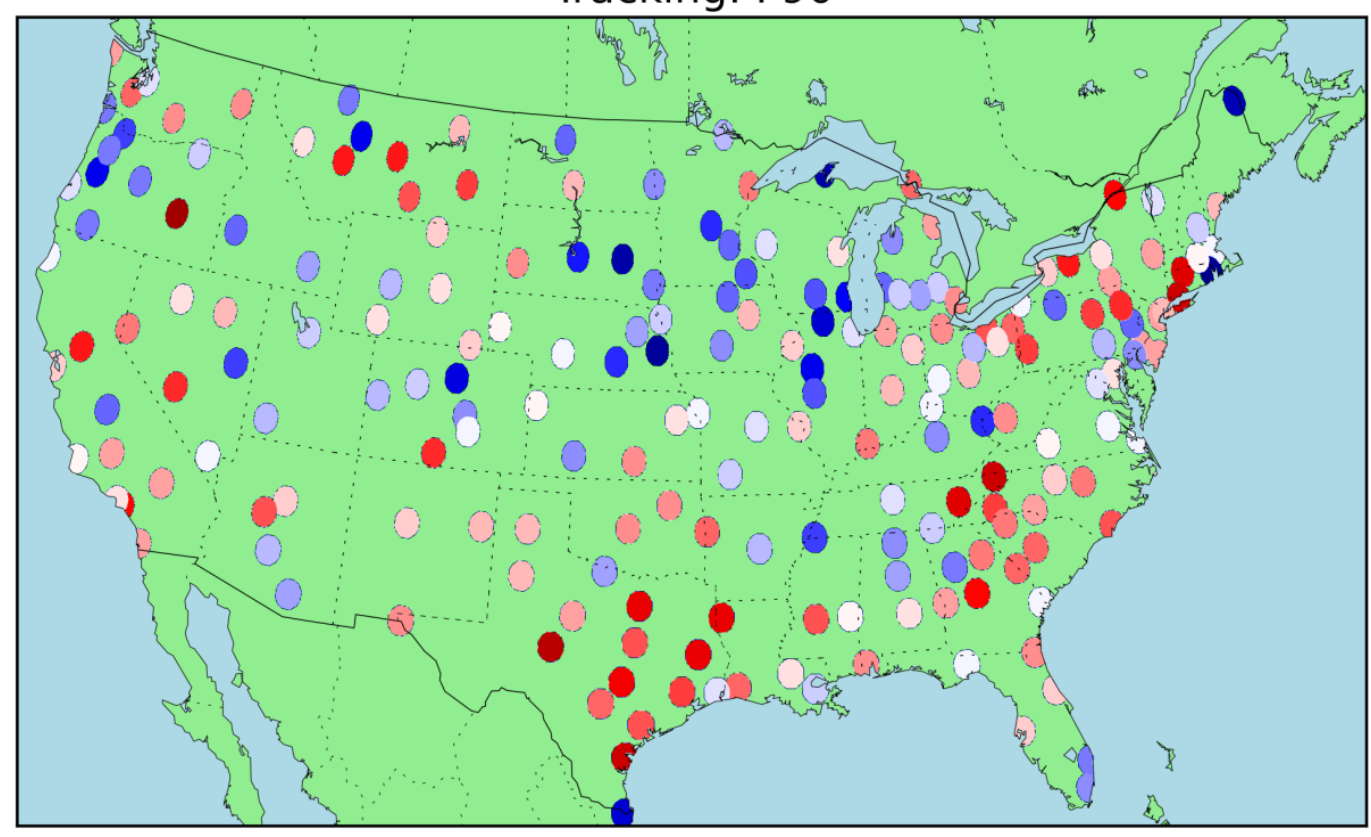

$-1.18$

$-2.08$

$-2.98$

$-3.88$

$-4.78$

$-5.68$

$-6.58$

$-7.48$

$-8.38$

$-9.28$

Figure 3. Normalized P90 map

Maps showing the P90 energy value (as a function of interannual variability only), expressed as a percent difference from the TMY energy prediction at each location in the TMY2 data set for both the fixed-tilt systems and the one-axis tracking systems 
The maps do not depict any obvious national trends, which may suggest that the interannual variability of annual $\mathrm{PV}$ production depends much more on local climates than it does on national weather patterns. Once higher spatial resolutions data sets become available, a more detailed investigation into these trends can be conducted.

Nevertheless, because these values are reported as a percent difference, these maps can be used as a starting point for future variability estimates by scaling the results of a TMY simulation by the reported normalized P90 energy value of the nearest TMY2 site. For instance, if a fixed-tilt PV system were to be installed near Boulder Colorado and a TMY simulation reported that the system would produce $12,000 \mathrm{kWh}$, then one can subtract $7.11 \%$ (Boulder's normalized P90 value from Figure 3a) from this value to obtain a P90 production value of $11,147 \mathrm{kWh}$, with respect to interannual variability. Similarly the P10 production for this system could be found by adding 2.95\% (from Table B.1) to the original TMY value obtaining 12,354 kWh. Thus one could reasonably determine the range which should contain the majority of this system's annual energy production, excluding other sources of uncertainty. Of course, these scaling factors do not take in to account shading effects, snow coverage, component failures, and other sources of variance which may be particular to the location or system design in question and so should not be considered to give definite results.

Figure 4 provides the standard deviations at each location after the data has been normalized by the TMY energy prediction at each location. As discussed previously, assuming a normal distribution may not be the best distribution to fit the results; nevertheless, this quantity will still contain meaningful information about the variability of solar energy production at each location. From these maps one can clearly see that for most locations both system designs (although it is much more pronounced for the fixed-tilt systems) had standard deviations in the $1.5 \%-4.5 \%$ range, with an average of $3.3 \%$. Once again, these maps do not show a general trend in PV variability for the continental United States, but they can still be used as a point of reference for future variability estimations by scaling the results of a TMY simulation by using the same procedure discussed for the $\mathrm{P} 90$ values.

Please see Appendix A for maps of the mean, P10, and P50 energy values at each location, and Appendix B for the tabulated values. 
Fixed: STD/TMY
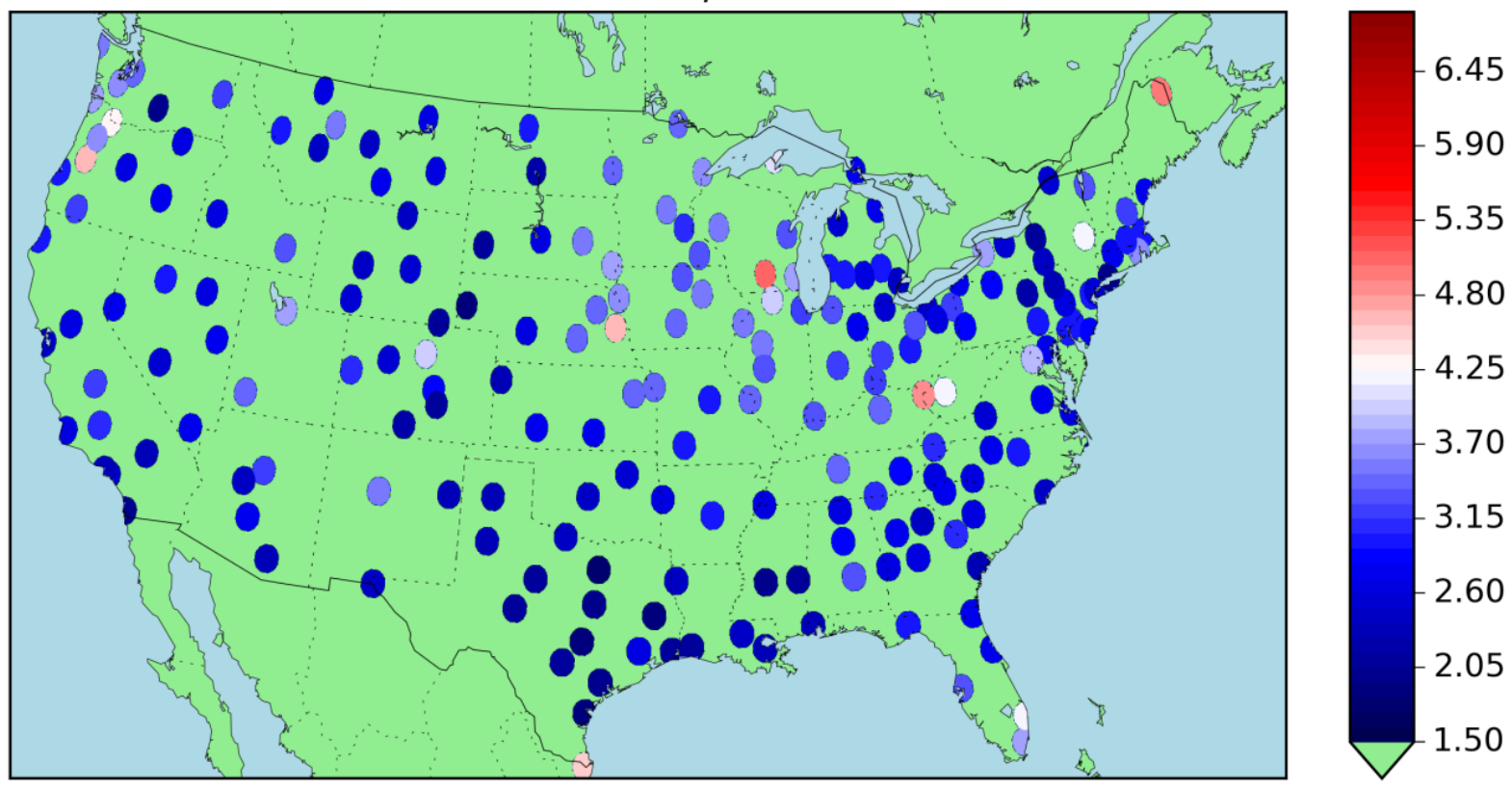

\section{Tracking: STD/TMY}
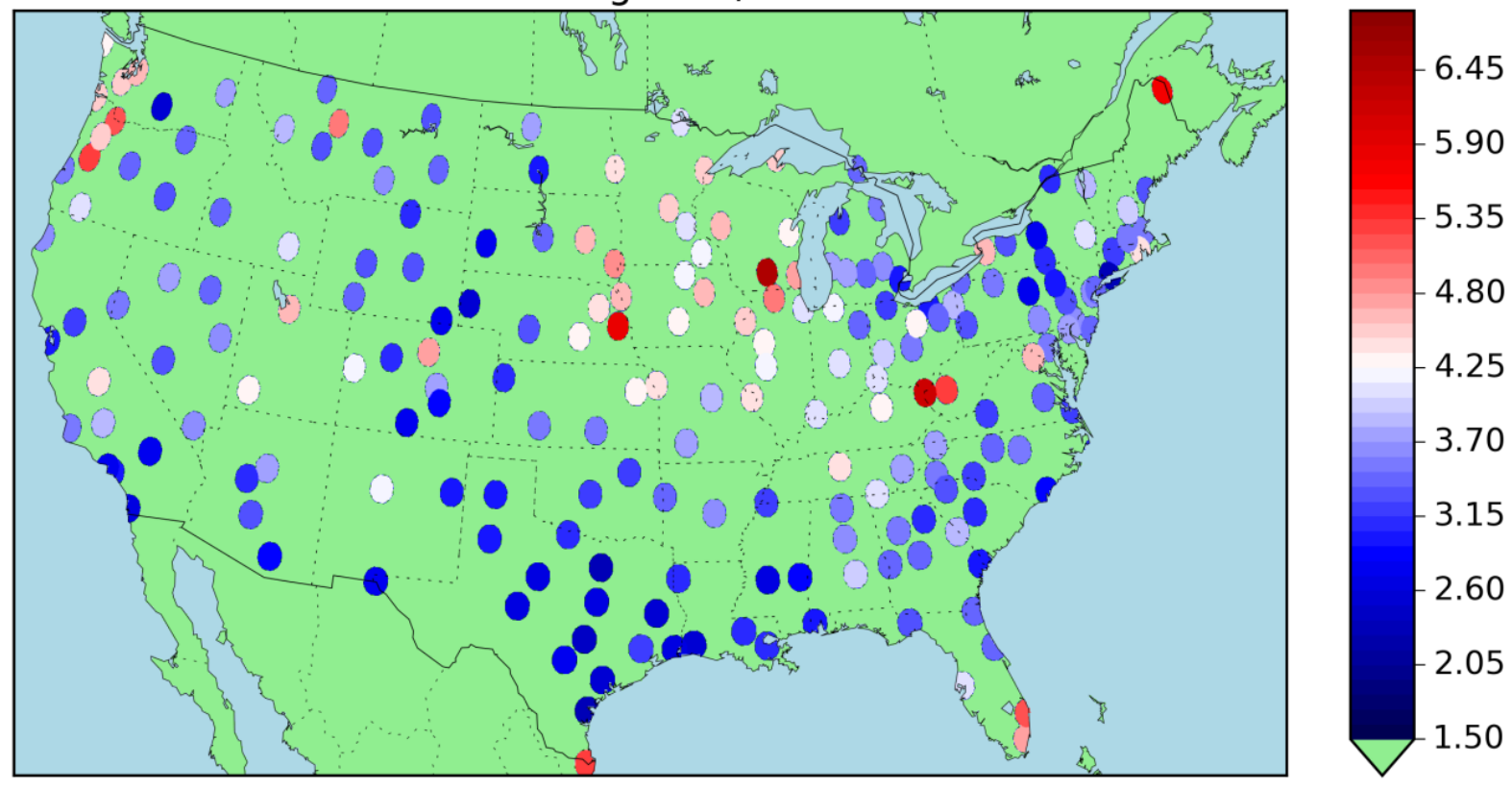

Figure 4. Standard Deviation Map

Maps showing the standard deviation as a percentage of the TMY energy prediction at each location in the TMY2 data set. 


\section{Conclusion}

Solar resource variability is a major concern for investors interested in funding PV projects on both the commercial and industrial scales. By using tools like PVWatts, typical annual energy outputs can be predicted. However, much less is known about the variability of energy production from year to year.

This study of inter-annual variability simulated two typical PV system designs, a $20^{\circ}$ fixed-tilt and a $20^{\circ}$ one-axis tracking system, during a 30 -year time period at 239 locations across the United States. The results of these simulations were tabulated and analyzed, producing several useful statistical for determining variability at a particular location. Most notably, in each case we calculated the P90 value, the empirically determined annual energy production which has a $90 \%$ chance of being exceeded. We then normalized these values relative to the corresponding TMY annual energy production to allow for meaningful comparisons between locations and to assist in determining variability of future system designs. In our analysis we found that the average normalized P90 energy value with respect to interannual variability was $4.8 \%$ less than the associated TMY energy prediction, while the lowest P90 found was $9.2 \%$ less. Moreover, the average standard deviation of these simulations was found to be $3.3 \%$ of its associated TMY energy prediction while the largest was $6.5 \%$.

The two system designs were chosen because they are common in the PV industry, although many other PV designs are possible. As such, the results obtained during this study may not apply to systems that differ significantly from those used in this study. Additionally, this study only took into account weather variances and their effect on the variability of annual PV system production. A more detailed variability analysis of a specific system would require an analysis of other sources of variance as well; such as the likelihood of system malfunction or curtailment periods. Nevertheless, this study facilitates future variability estimations in which a TMY simulation of a desired system could be performed and the resulting annual energy estimation could be scaled by the P90, P10, or STD value of a nearby TMY2 location reported here. Values calculated from such an analysis would be sufficient for an initial estimation of interannual variability. 


\section{References}

[1] Freeman, Janine, Jonathan Whitmore, Nate Blair, and Aron P. Dobos. "Validation of Multiple Tools for Flat Plate Photovoltaic Modeling against Measured Data." Photovoltaic Specialist Conference (PVSC), 2014 IEEE 40th. IEEE, 2014.

[2] "National Solar Radiation Data Base: 1961-1990: Typical Meteorological Year 2." NSRDB (1995). Accessed March 2015: http://rredc.nrel.gov/solar/old_data/nsrdb/1961-1990/tmy2/.

[3] Dobos, A., P. Gilman, and M. Kasberg. "P50/P90 Analysis for Solar Energy Systems using the System Advisor Model." World Renew. Energy Forum, Denver, CO, USA. 2012. 


\section{Appendix A: Alternative Maps}

Fixed: Avg (kWh)

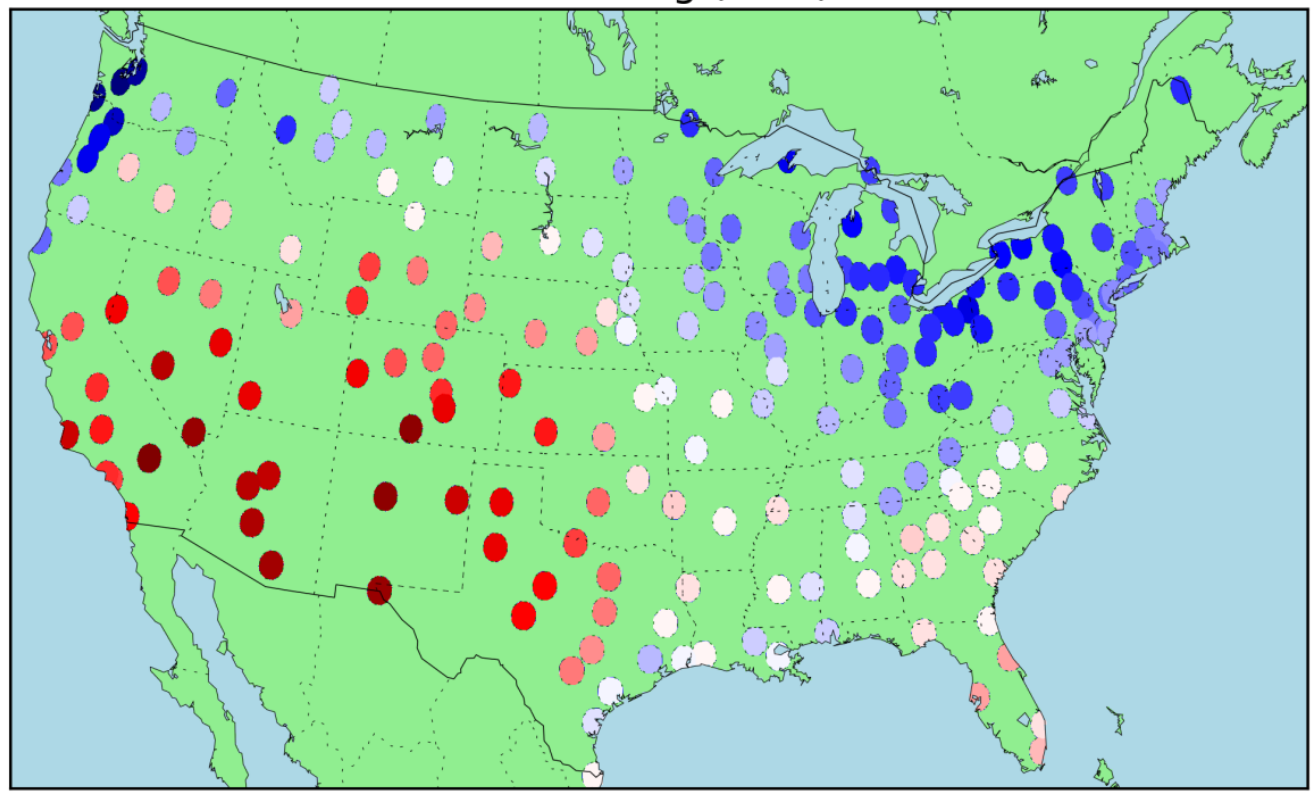

$-16900$

16123

15346

14570

13793

13016

12240

11463

10686

9910

\section{Tracking: Avg (kWh)}

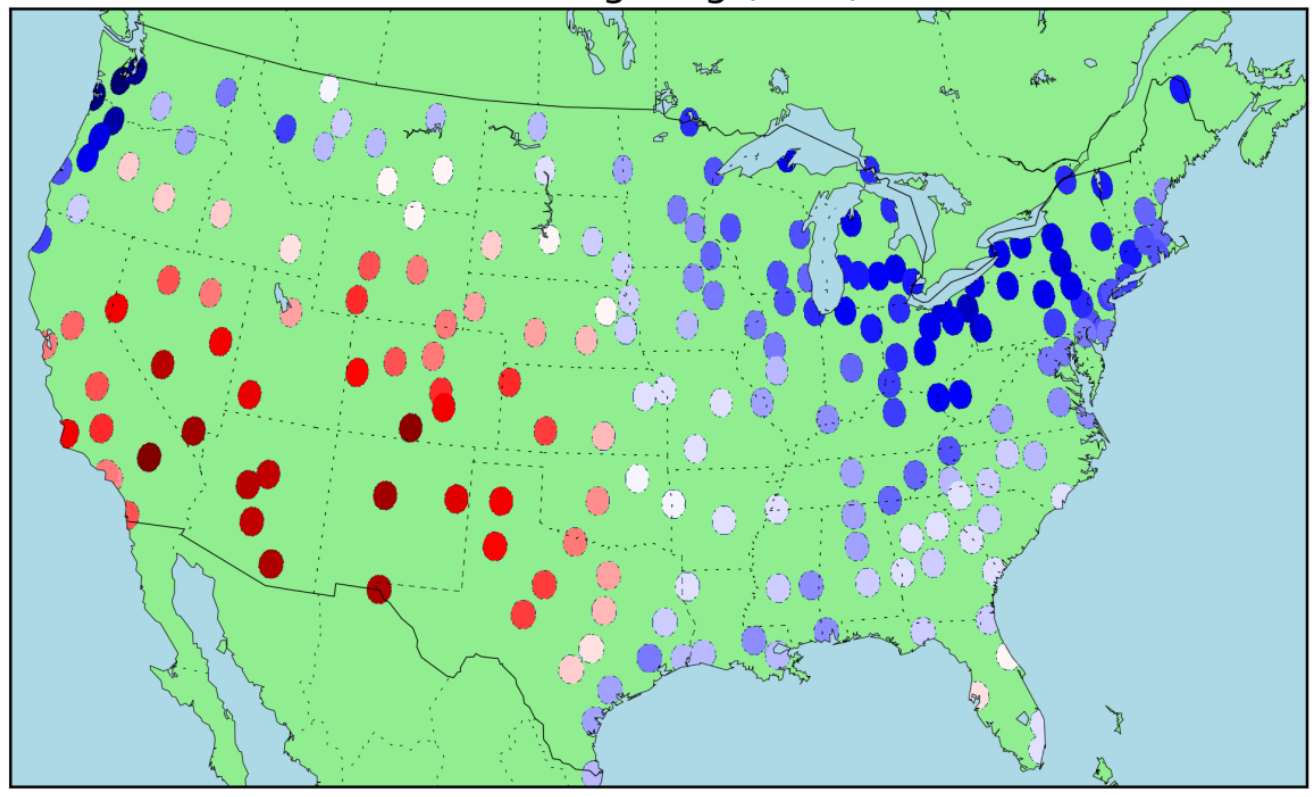

21711

20596

19480

18365

17250

16134

15019

13904

12789

11673

Figure A.1. Map of the average annual energy evaluated at each TMY2 location

Average values at each location which are not normalized. 

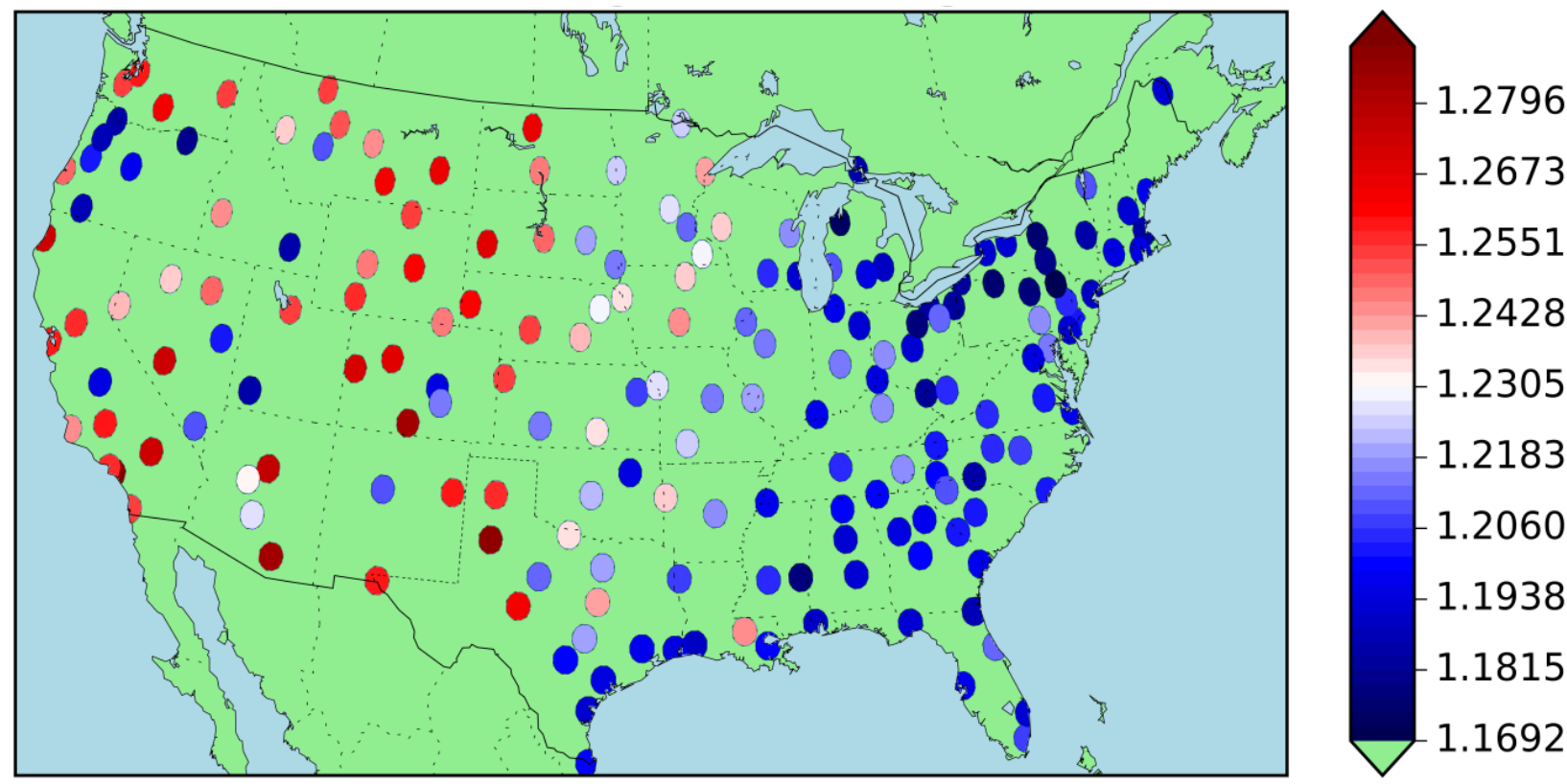

Figure A.2. Average energy production relative difference (tracking/fixed)

The average annual energy for the one-axis tracking systems is divided by that of the fixed-tilt systems at each location. Although all values are greater than 1 , which is an expected outcome, this plot shows where in the United States a one-axis tracking system is most beneficial. 
Fixed: P50
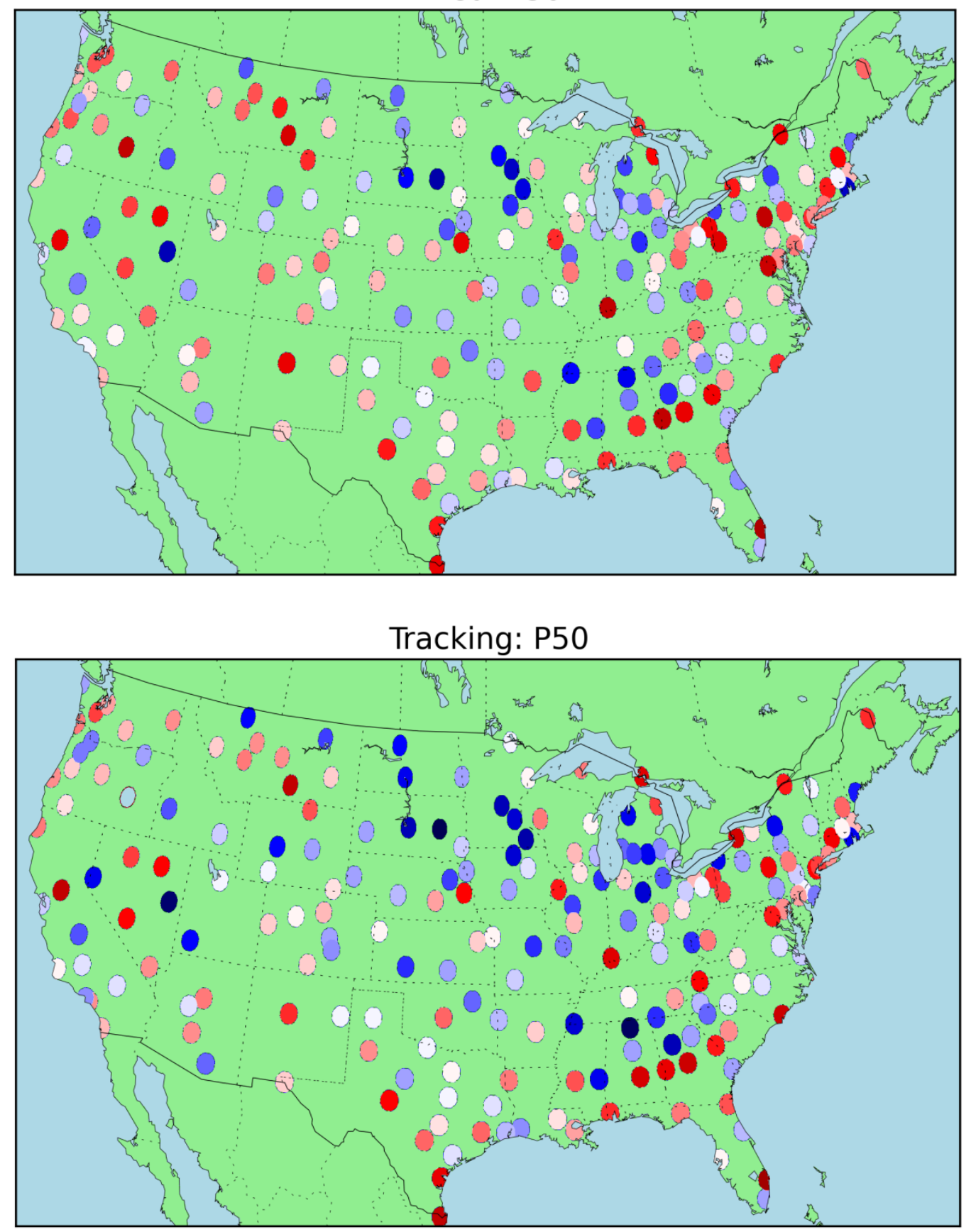

1.664

1.104

0.544

$-0.016$

$-0.576$

$-1.136$

$-1.696$

$-2.256$

$-2.816$

$-3.376$

Figure A.3. Normalized P50 energy values at each location 
Fixed: P10

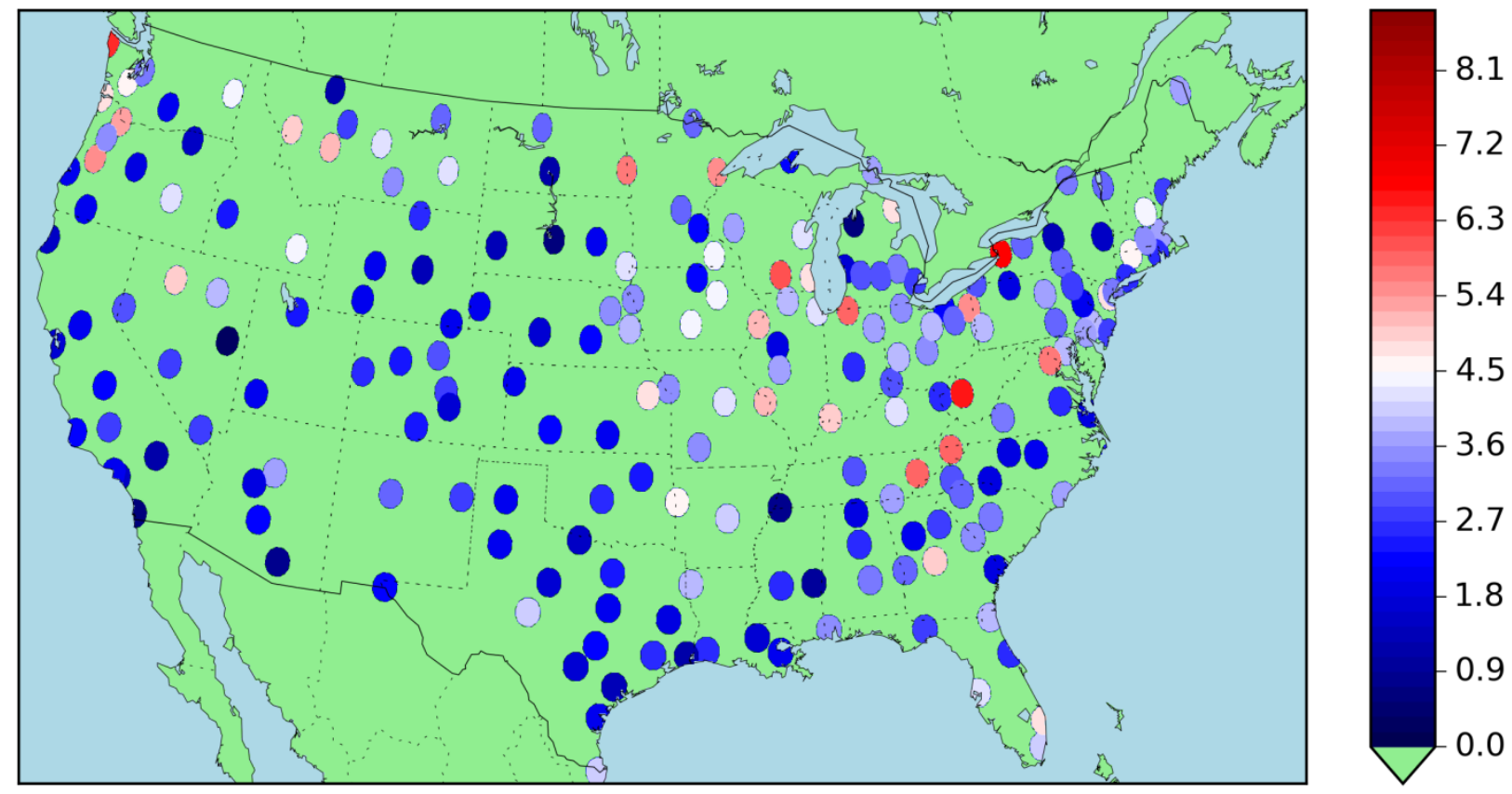

Tracking: P10
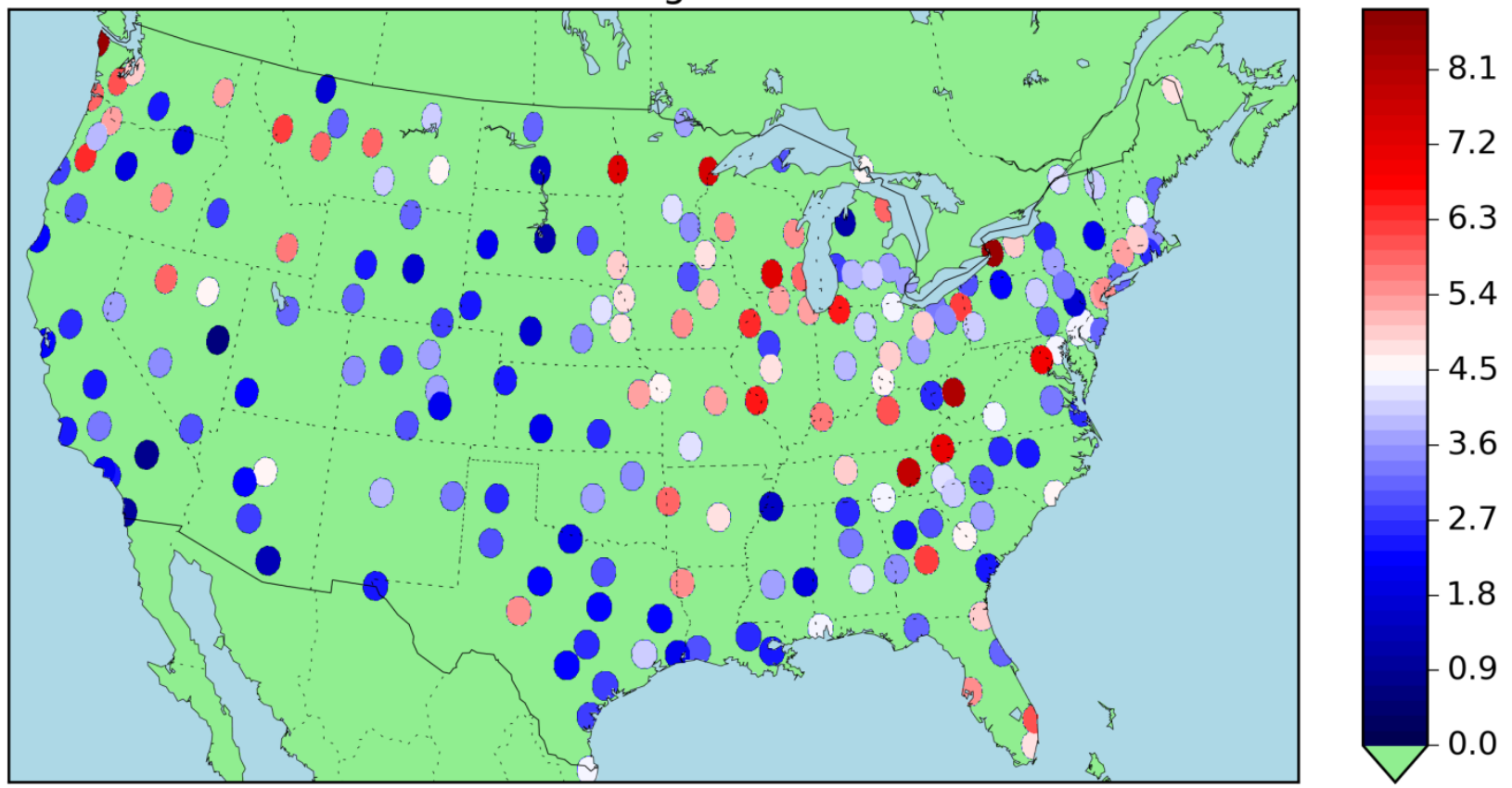

Figure A.4. Normalized P10 energy values at each location 


\section{Appendix B: Tabulated Results}

Note: All values are reported as a percent difference from the TMY energy prediction. Note that these P90, P50, and P10 values do not represent the overall energy uncertainty; rather, they represent this sample of data, where the only uncertainty is the interannual weather variability.

Table B.1. Tabulated Values for Each Location in the TMY2 Data Set

\begin{tabular}{|c|c|c|c|c|c|c|c|c|c|c|c|}
\hline \multirow{2}{*}{ State } & \multirow{2}{*}{ City } & \multirow{2}{*}{ Lat } & \multirow{2}{*}{ Lon } & \multicolumn{4}{|c|}{ Fixed-Tilt Systems } & \multicolumn{4}{|c|}{ One-Axis Tracking } \\
\hline & & & & P90 & P50 & $\mathrm{P} 10$ & STD & P90 & P50 & P10 & STD \\
\hline AK & Anchorage & 61.17 & -150.02 & -6.27 & -0.79 & 3.49 & 3.31 & -7.13 & -0.47 & 5.61 & 4.31 \\
\hline AK & Annette & 55.03 & -131.57 & -8.89 & -0.77 & 2.35 & 5.09 & -10.04 & -0.79 & 4.54 & 6.14 \\
\hline AK & Barrow & 71.3 & -156.78 & -6.07 & 0.11 & 4.75 & 4.02 & -8.43 & -0.56 & 6.12 & 5.56 \\
\hline AK & Bethel & 60.78 & -161.8 & -4.93 & -0.28 & 6.1 & 4.74 & -5.82 & 0.09 & 9.52 & 5.91 \\
\hline AK & Bettles & 66.92 & -151.52 & -10.21 & 0.44 & 4.09 & 5.8 & -12.89 & 0.08 & 5.31 & 7.42 \\
\hline AK & Big Delta & 64 & -145.73 & -5.95 & 0.43 & 5.46 & 4.14 & -6.39 & 1.42 & 8.88 & 5.47 \\
\hline AK & Cold Bay & 55.2 & -162.72 & -4.7 & 2.03 & 8.32 & 5.58 & -5.74 & 0.33 & 8.91 & 6.3 \\
\hline AK & Fairbanks & 64.82 & -147.87 & -4.9 & 0.14 & 5 & 3.71 & -6.49 & 0 & 6.58 & 4.92 \\
\hline AK & Gulkana & 62.15 & -145.45 & -4.35 & 1.78 & 7.05 & 4.14 & -5.78 & 1.57 & 8.7 & 5.37 \\
\hline AK & King Salmon & 58.68 & -156.65 & -6.34 & -1.1 & 7.4 & 5.35 & -8.65 & -1.89 & 8.62 & 6.38 \\
\hline AK & Kodiak & 57.75 & -152.33 & -8.48 & -0.3 & 4.48 & 5.43 & -8.56 & -0.63 & 6.39 & 6.5 \\
\hline AK & Kotzebue & 66.87 & -162.63 & -4.19 & 3.67 & 9.01 & 5.8 & -6.14 & 4.69 & 12.32 & 7.96 \\
\hline AK & McGrath & 62.97 & -155.62 & -7.11 & -0.9 & 4.19 & 4.99 & -8.32 & -0.88 & 5.54 & 6.48 \\
\hline AK & Nome & 64.5 & -165.43 & -7.53 & 0.7 & 7.16 & 5.51 & -9.24 & 0.75 & 7.61 & 7.19 \\
\hline AK & St Paul Is. & 57.15 & -170.22 & -10.26 & -0.52 & 14.51 & 8.31 & -10.84 & -0.14 & 17.26 & 9.75 \\
\hline AK & Talkeetna & 62.3 & -150.1 & -3.83 & 0.43 & 5.27 & 3.95 & -5.41 & 1.64 & 7.16 & 5.17 \\
\hline AK & Yakutat & 59.52 & -139.67 & -10.57 & -1.23 & 3.1 & 5.48 & -11.17 & -3.37 & 4.52 & 5.91 \\
\hline$A L$ & Birmingham & 33.57 & -86.75 & -5.12 & -1.51 & 2.68 & 2.85 & -6.27 & -1.35 & 3.41 & 3.6 \\
\hline$A L$ & Huntsville & 34.65 & -86.77 & -5.08 & -2.32 & 1.95 & 2.67 & -6.58 & -3.38 & 2.54 & 3.49 \\
\hline $\mathrm{AL}$ & Mobile & 30.68 & -88.25 & -3 & 0.33 & 3.54 & 2.3 & -4.49 & 0.35 & 4.49 & 3.02 \\
\hline$A L$ & Montgomery & 32.3 & -86.4 & -4.48 & 0.34 & 3.32 & 3.28 & -5.27 & 1.07 & 4.2 & 3.94 \\
\hline AR & Fort Smith & 35.33 & -94.37 & -3.27 & -1.15 & 4.54 & 2.63 & -4.2 & -1.16 & 5.84 & 3.39 \\
\hline AR & Little Rock & 34.73 & -92.23 & -4.83 & 0.19 & 4.07 & 2.96 & -6.18 & -0.54 & 4.68 & 3.66 \\
\hline$A Z$ & Flagstaff & 35.13 & -111.67 & -4.61 & -0.07 & 3.71 & 3.19 & -4.98 & -0.11 & 4.68 & 3.81 \\
\hline $\mathbf{A Z}$ & Phoenix & 33.43 & -112.02 & -5.01 & -0.42 & 2.23 & 2.73 & -6.15 & -0.14 & 2.79 & 3.35 \\
\hline $\mathbf{A Z}$ & Prescott & 34.65 & -112.43 & -3.36 & -0.74 & 1.96 & 2.47 & -4.01 & -0.92 & 2.21 & 3.06 \\
\hline$A Z$ & Tucson & 32.12 & -110.93 & -5.47 & -1.26 & 0.84 & 2.34 & -6.3 & -1.61 & 1.31 & 2.91 \\
\hline CA & Arcata & 40.98 & -124.1 & -4.56 & -0.47 & 1.45 & 2.96 & -5.68 & -0.11 & 2.2 & 3.66 \\
\hline
\end{tabular}

This report is available from the National Renewable Energy Laboratory (NREL) at www.nrel.gov/publications. 


\begin{tabular}{|c|c|c|c|c|c|c|c|c|c|c|c|}
\hline \multirow{2}{*}{ State } & \multirow{2}{*}{ City } & \multirow{2}{*}{ Lat } & \multirow{2}{*}{ Lon } & \multicolumn{4}{|c|}{ Fixed-Tilt Systems } & \multicolumn{4}{|c|}{ One-Axis Tracking } \\
\hline & & & & P90 & P50 & $\mathrm{P} 10$ & STD & P90 & P50 & $\mathrm{P} 10$ & STD \\
\hline CA & Bakersfield & 35.42 & -119.05 & -3.75 & -0.62 & 2.72 & 3.08 & -4.77 & -0.96 & 3.37 & 3.83 \\
\hline CA & Daggett & 34.87 & -116.78 & -4.67 & -0.69 & 1.25 & 2.28 & -4.7 & -0.95 & 0.88 & 2.72 \\
\hline CA & Fresno & 36.77 & -119.72 & -5.02 & -1.55 & 2.22 & 3.16 & -6.87 & -1.79 & 2.43 & 4.38 \\
\hline CA & Long Beach & 33.82 & -118.15 & -2.82 & -0.75 & 1.49 & 2.4 & -3.18 & -0.18 & 2.34 & 2.96 \\
\hline CA & Los Angeles & 33.93 & -118.4 & -4.73 & -0.83 & 2.09 & 2.34 & -5.23 & -1.4 & 2.05 & 2.74 \\
\hline CA & Sacramento & 38.52 & -121.5 & -2.32 & 0.87 & 2.04 & 2.63 & -3.38 & 1.25 & 2.59 & 3.19 \\
\hline CA & San Diego & 32.73 & -117.17 & -3.88 & -0.37 & 0.63 & 2.04 & -4.67 & -0.37 & 1.04 & 2.63 \\
\hline CA & San Francisco & 37.62 & -122.38 & -3.91 & -0.95 & 1.7 & 2.44 & -5.03 & -1.05 & 2.3 & 3.01 \\
\hline CA & Santa Maria & 34.9 & -120.45 & -3.92 & -0.56 & 2.3 & 2.7 & -5.34 & -0.73 & 2.43 & 3.51 \\
\hline co & Alamosa & 37.45 & -105.87 & -2.82 & -0.24 & 2.48 & 2.21 & -3.61 & -0.52 & 2.93 & 2.71 \\
\hline CO & Boulder & 40.02 & -105.25 & -7.11 & -0.08 & 2.95 & 3.97 & -8.05 & -0.38 & 3.66 & 4.75 \\
\hline CO & Colorado Springs & 38.82 & -104.72 & -5.31 & -0.76 & 2.7 & 2.87 & -6.53 & -1.35 & 3.67 & 3.76 \\
\hline CO & Eagle & 39.65 & -106.92 & -4.14 & -0.51 & 2.5 & 2.52 & -5.89 & -0.78 & 2.72 & 3.15 \\
\hline CO & Grand Junction & 39.12 & -108.53 & -4.39 & -0.1 & 2.56 & 3.08 & -6.08 & -0.54 & 3.52 & 4.22 \\
\hline CO & Pueblo & 38.28 & -104.52 & -4.16 & -0.95 & 1.75 & 2.14 & -5.52 & -1.43 & 2.06 & 2.88 \\
\hline CT & Bridgeport & 41.17 & -73.13 & -2.35 & -0.09 & 2.52 & 1.96 & -2.36 & -0.2 & 3.17 & 2.3 \\
\hline CT & Hartford & 41.93 & -72.68 & -2.16 & 0.48 & 4.6 & 2.75 & -2.75 & 0.75 & 5.35 & 3.17 \\
\hline DE & Wilmington & 39.67 & -75.6 & -4.94 & -0.04 & 3.64 & 2.98 & -6.47 & -0.31 & 4.4 & 3.7 \\
\hline FL & Daytona Beach & 29.18 & -81.05 & -4.37 & -1.41 & 2.69 & 2.77 & -4.99 & -1.24 & 3.17 & 3.45 \\
\hline FL & Jacksonville & 30.5 & -81.7 & -3.57 & 0.01 & 3.89 & 2.77 & -4.53 & 0.2 & 5 & 3.43 \\
\hline FL & Key West & 24.55 & -81.75 & -3 & -0.75 & 2.66 & 2.03 & -3.91 & -1.16 & 3.55 & 2.72 \\
\hline FL & Miami & 25.8 & -80.27 & -5.08 & -1.15 & 3.99 & 3.79 & -6.45 & -1.33 & 4.8 & 4.74 \\
\hline FL & Tallahassee & 30.38 & -84.37 & -5.57 & -0.01 & 2.87 & 2.99 & -5.55 & -0.03 & 3.18 & 3.36 \\
\hline FL & Tampa & 27.97 & -82.53 & -4.26 & -0.75 & 4.32 & 3.27 & -5.12 & -0.76 & 5.48 & 4.06 \\
\hline FL & West Palm Beach & 26.68 & -80.1 & -5.51 & 1.48 & 4.8 & 4.16 & -6.61 & 1.56 & 6.08 & 5.19 \\
\hline GA & Athens & 33.95 & -83.32 & -3.43 & -0.91 & 2.71 & 2.47 & -4.38 & -1.27 & 2.97 & 3.07 \\
\hline GA & Atlanta & 33.65 & -84.43 & -5.07 & -2.02 & 2.02 & 2.77 & -6.69 & -2.72 & 2.36 & 3.52 \\
\hline GA & Augusta & 33.37 & -81.97 & -3.46 & 0.74 & 3.52 & 3.07 & -4.2 & 0.46 & 4.62 & 3.89 \\
\hline GA & Columbus & 32.52 & -84.95 & -3.32 & 1.28 & 3.21 & 2.68 & -4.76 & 0.86 & 3.5 & 3.37 \\
\hline GA & Macon & 32.7 & -83.65 & -2.42 & 0.86 & 4.91 & 2.62 & -3.19 & 1.2 & 6.16 & 3.44 \\
\hline GA & Savannah & 32.13 & -81.2 & -4.1 & -1.16 & 1.98 & 2.34 & -5.58 & -1.35 & 2.35 & 2.98 \\
\hline HI & Hilo & 19.72 & -155.07 & -4.51 & -0.39 & 3.9 & 3.53 & -6.16 & -0.63 & 5.26 & 4.47 \\
\hline HI & Honolulu & 21.33 & -157.92 & -2.99 & -0.46 & 3.01 & 2.42 & -4.17 & -1.37 & 2.93 & 2.97 \\
\hline
\end{tabular}

This report is available from the National Renewable Energy Laboratory (NREL) at www.nrel.gov/publications. 


\begin{tabular}{|c|c|c|c|c|c|c|c|c|c|c|c|}
\hline \multirow{2}{*}{ State } & \multirow{2}{*}{ City } & \multirow{2}{*}{ Lat } & \multirow{2}{*}{ Lon } & \multicolumn{4}{|c|}{ Fixed-Tilt Systems } & \multicolumn{4}{|c|}{ One-Axis Tracking } \\
\hline & & & & P90 & P50 & P10 & STD & P90 & P50 & $\mathrm{P} 10$ & STD \\
\hline HI & Kahului & 20.9 & -156.43 & -4.81 & 0.93 & 4.47 & 3.6 & -6.14 & 0.49 & 5.64 & 4.56 \\
\hline HI & Lihue & 21.98 & -159.35 & -2.78 & -0.29 & 4.68 & 3.05 & -3.73 & -0.45 & 4.66 & 3.94 \\
\hline IA & Des Moines & 41.53 & -93.65 & -4.57 & -0.74 & 4.41 & 3.43 & -6.5 & -1.32 & 5.45 & 4.33 \\
\hline IA & Mason City & 43.15 & -93.33 & -5.89 & -1.95 & 2.27 & 3.28 & -6.91 & -2.56 & 2.94 & 4.2 \\
\hline IA & Sioux City & 42.4 & -96.38 & -4.81 & -1.34 & 3.57 & 3.61 & -6.02 & -1.33 & 4.72 & 4.67 \\
\hline IA & Waterloo & 42.55 & -92.4 & -3.49 & -0.5 & 4.34 & 3.53 & -4.91 & -1 & 5.13 & 4.59 \\
\hline ID & Boise & 43.57 & -116.22 & -5.42 & -1.72 & 2.34 & 2.69 & -6.76 & -1.73 & 2.72 & 3.47 \\
\hline ID & Pocatello & 42.92 & -112.6 & -4.45 & -0.53 & 4.48 & 3.26 & -6.23 & -1.03 & 5.67 & 4.1 \\
\hline IL & Chicago & 41.78 & -87.75 & -4.27 & -1.17 & 4.19 & 3.23 & -5.83 & -1.99 & 5.32 & 4.06 \\
\hline IL & Moline & 41.45 & -90.52 & -3.66 & 0.33 & 5.07 & 3.54 & -5.1 & 0.45 & 6.44 & 4.51 \\
\hline IL & Peoria & 40.67 & -89.68 & -6.61 & -1.66 & 1.87 & 3.49 & -7.92 & -1.87 & 2.7 & 4.36 \\
\hline IL & Rockford & 42.2 & -89.1 & -6.35 & -0.56 & 3.88 & 4.01 & -8.28 & -0.61 & 5.39 & 4.96 \\
\hline IL & Springfield & 39.83 & -89.67 & -5.81 & -0.05 & 3.72 & 3.28 & -6.98 & -0.44 & 4.83 & 4.14 \\
\hline IN & Evansville & 38.05 & -87.53 & -3.21 & 1.22 & 5 & 3.28 & -4.37 & 0.89 & 5.7 & 4.09 \\
\hline IN & Fort Wayne & 41 & -85.2 & -4.24 & -2.03 & 3.63 & 2.8 & -4.98 & -2.49 & 4.04 & 3.45 \\
\hline IN & Indianapolis & 39.73 & -86.28 & -4.29 & -1.49 & 2.57 & 3.15 & -4.84 & -1.58 & 3.85 & 4.07 \\
\hline IN & South Bend & 41.7 & -86.32 & -3.87 & -1.06 & 5.85 & 3.27 & -4.61 & -0.57 & 6.51 & 4.19 \\
\hline KS & Dodge City & 37.77 & -99.97 & -5.18 & -1.43 & 2.21 & 2.75 & -6.49 & -1.94 & 2.14 & 3.48 \\
\hline KS & Goodland & 39.37 & -101.7 & -3.72 & -0.41 & 2.04 & 2.33 & -5.32 & -0.72 & 2.39 & 3.05 \\
\hline KS & Topeka & 39.07 & -95.63 & -4.33 & -0.05 & 4.86 & 3.42 & -5.27 & -0.56 & 5.38 & 4.3 \\
\hline KS & Wichita & 37.65 & -97.42 & -3.62 & -1.21 & 2.15 & 2.73 & -4.54 & -1.28 & 2.53 & 3.52 \\
\hline KY & Covington & 39.07 & -84.67 & -4.83 & -0.73 & 2.95 & 3.18 & -5.54 & -0.99 & 4.64 & 4.1 \\
\hline KY & Lexington & 38.03 & -84.6 & -5.43 & -1.19 & 4.22 & 3.45 & -6.47 & -1.09 & 6.02 & 4.35 \\
\hline LA & Baton Rouge & 30.53 & -91.15 & -4 & -0.94 & 1.75 & 2.38 & -5.23 & -0.6 & 2.66 & 3.05 \\
\hline LA & Lake Charles & 30.12 & -93.22 & -3.22 & -0.59 & 2.7 & 2.09 & -4.15 & -1.37 & 3 & 2.59 \\
\hline LA & New Orleans & 29.98 & -90.25 & -4.57 & -0.61 & 1.99 & 2.37 & -5.91 & -0.3 & 2.37 & 3.06 \\
\hline LA & Shreveport & 32.47 & -93.82 & -2.37 & -0.18 & 3.89 & 2.39 & -2.81 & -0.08 & 5.41 & 3.14 \\
\hline MA & Boston & 42.37 & -71.03 & -4.02 & -0.41 & 3.64 & 2.96 & -5.64 & -0.43 & 3.56 & 3.53 \\
\hline MA & Worchester & 42.27 & -71.87 & -4.28 & -0.84 & 3.58 & 2.98 & -5.47 & -0.78 & 4.87 & 3.56 \\
\hline MD & Baltimore & 39.18 & -76.67 & -4.43 & -0.22 & 3.85 & 2.81 & -5.28 & -0.22 & 4.34 & 3.55 \\
\hline ME & Caribou & 46.87 & -68.02 & -8.88 & 0.06 & 3.77 & 5 & -8.67 & 0.36 & 4.84 & 5.73 \\
\hline ME & Portland & 43.65 & -70.32 & -4.2 & -1.69 & 2.81 & 2.8 & -4.93 & -2.05 & 3.18 & 3.29 \\
\hline MI & Alpena & 45.07 & -83.57 & -3.41 & 0.56 & 4.72 & 2.82 & -4.78 & 0.26 & 5.85 & 3.53 \\
\hline
\end{tabular}

This report is available from the National Renewable Energy Laboratory (NREL) at www.nrel.gov/publications. 


\begin{tabular}{|c|c|c|c|c|c|c|c|c|c|c|c|}
\hline \multirow{2}{*}{ State } & \multirow{2}{*}{ City } & \multirow{2}{*}{ Lat } & \multirow{2}{*}{ Lon } & \multicolumn{4}{|c|}{ Fixed-Tilt Systems } & \multicolumn{4}{|c|}{ One-Axis Tracking } \\
\hline & & & & P90 & P50 & P10 & STD & P90 & P50 & $\mathrm{P} 10$ & STD \\
\hline MI & Detroit & 42.42 & -83.02 & -3.57 & -1.08 & 2.82 & 2.45 & -4.43 & -1.14 & 3.78 & 3.04 \\
\hline MI & Flint & 42.97 & -83.73 & -4.74 & -0.4 & 3.3 & 2.96 & -6 & -1.36 & 3.64 & 3.6 \\
\hline MI & Grand Rapids & 42.88 & -85.52 & -4.83 & -1.23 & 2.93 & 2.99 & -5.99 & -1.82 & 3.85 & 3.76 \\
\hline MI & Houghton & 47.17 & -88.5 & -8.75 & -0.7 & 2.28 & 4.13 & -8.91 & -0.02 & 2.94 & 4.57 \\
\hline MI & Lansing & 42.78 & -84.6 & -4.87 & -1.66 & 3.05 & 2.69 & -6.23 & -2.32 & 4.12 & 3.44 \\
\hline MI & Muskegon & 43.17 & -86.25 & -5.75 & -1.71 & 1.79 & 2.98 & -6.93 & -1.64 & 2.79 & 3.76 \\
\hline MI & Sault Ste. Marie & 46.47 & -84.37 & -3.79 & 0.39 & 3.71 & 2.82 & -4.24 & 0.92 & 4.54 & 3.46 \\
\hline MI & Traverse City & 44.73 & -85.58 & -5.23 & -1.82 & 0.69 & 2.57 & -6.52 & -2.27 & 1.23 & 3.2 \\
\hline MN & Duluth & 46.83 & -92.18 & -4.12 & -0.77 & 5.57 & 3.6 & -4.29 & -0.72 & 7.49 & 4.56 \\
\hline MN & International Falls & 48.57 & -93.38 & -5.34 & -1.24 & 3.18 & 3.39 & -6.1 & -0.91 & 3.71 & 4.04 \\
\hline MN & Minneapolis & 44.88 & -93.22 & -5.08 & -2.65 & 2.28 & 3.13 & -6.81 & -2.52 & 3.44 & 4.12 \\
\hline MN & Rochester & 43.92 & -92.5 & -4.78 & -2.38 & 4.43 & 3.26 & -7.07 & -2.85 & 4.74 & 4.2 \\
\hline MN & Saint Cloud & 45.55 & -94.07 & -6.11 & -2.22 & 3.16 & 3.54 & -7.45 & -2.73 & 4.23 & 4.49 \\
\hline MO & Columbia & 38.82 & -92.22 & -4.42 & -1.28 & 4.15 & 2.99 & -5.77 & -1.99 & 5.23 & 3.81 \\
\hline MO & Kansas City & 39.3 & -94.72 & -4.38 & -1.12 & 3.45 & 3.44 & -5.59 & -0.78 & 4.55 & 4.42 \\
\hline MO & Springfield & 37.23 & -93.38 & -4.72 & -1.04 & 3.49 & 3.02 & -5.9 & -1.03 & 4.28 & 3.8 \\
\hline MO & St. Louis & 38.75 & -90.38 & -4.16 & -0.89 & 5.15 & 3.47 & -5.06 & -1.51 & 6.53 & 4.38 \\
\hline MS & Jackson & 32.32 & -90.08 & -2.31 & 0.28 & 2.53 & 2.03 & -3.96 & 0.12 & 3.69 & 2.69 \\
\hline MS & Meridian & 32.33 & -88.75 & -4.21 & -1.82 & 1.02 & 2.1 & -5.44 & -2.27 & 1.85 & 2.87 \\
\hline MT & Billings & 45.8 & -108.53 & -3.15 & 1.04 & 3.51 & 2.74 & -3.98 & 1.24 & 4.14 & 3.59 \\
\hline MT & Cut Bank & 48.6 & -112.37 & -5.21 & -1.7 & 1.23 & 2.66 & -6.62 & -2.21 & 1.74 & 3.37 \\
\hline MT & Glasgow & 48.22 & -106.62 & -4.6 & -1.47 & 3.12 & 2.69 & -4.96 & -1.89 & 3.97 & 3.3 \\
\hline MT & Great Falls & 47.48 & -111.37 & -4.74 & 0.12 & 2.86 & 3.52 & -7.96 & -0.2 & 3.17 & 5 \\
\hline MT & Helena & 46.6 & -112 & -2.52 & 0.09 & 5.11 & 2.44 & -3.44 & -0.02 & 5.88 & 3.31 \\
\hline MT & Lewistown & 47.05 & -109.45 & -2.43 & 0.52 & 4.26 & 2.48 & -3.46 & -0.2 & 5.88 & 3.31 \\
\hline MT & Miles City & 46.43 & -105.87 & -2.81 & -0.5 & 4.2 & 2.65 & -3.81 & -0.55 & 4.62 & 3.43 \\
\hline MT & Missoula & 46.92 & -114.08 & -4.52 & -0.36 & 4.94 & 2.96 & -5.24 & -0.48 & 6.16 & 3.81 \\
\hline NC & Asheville & 35.43 & -82.53 & -3.32 & -0.53 & 2.99 & 2.7 & -3.72 & -1.2 & 4.29 & 3.55 \\
\hline NC & Cape Hatteras & 35.27 & -75.55 & -3.97 & -0.05 & 2.6 & 2.55 & -5.06 & -0.12 & 3.52 & 3.13 \\
\hline NC & Charlotte & 35.22 & -80.93 & -4.17 & -0.93 & 1.92 & 2.66 & -4.62 & -0.97 & 2.93 & 3.24 \\
\hline NC & Greensboro & 36.08 & -79.95 & -4.57 & -1.03 & 1.86 & 2.76 & -5.1 & -0.8 & 2.6 & 3.37 \\
\hline NC & Raleigh & 35.87 & -78.78 & -4.23 & -1.02 & 2.05 & 2.94 & -4.4 & -0.93 & 2.49 & 3.5 \\
\hline NC & Wilmington & 34.27 & -77.9 & -2.95 & 0.34 & 3.61 & 2.4 & -3.97 & 1.11 & 4.56 & 2.92 \\
\hline
\end{tabular}

This report is available from the National Renewable Energy Laboratory (NREL) at www.nrel.gov/publications. 


\begin{tabular}{|c|c|c|c|c|c|c|c|c|c|c|c|}
\hline \multirow{2}{*}{ State } & \multirow{2}{*}{ City } & \multirow{2}{*}{ Lat } & \multirow{2}{*}{ Lon } & \multicolumn{4}{|c|}{ Fixed-Tilt Systems } & \multicolumn{4}{|c|}{ One-Axis Tracking } \\
\hline & & & & P90 & P50 & P10 & STD & P90 & P50 & P10 & STD \\
\hline ND & Bismarck & 46.77 & -100.75 & -3.65 & -1.42 & 1.1 & 2.25 & -4.85 & -2.34 & 1.46 & 2.94 \\
\hline ND & Fargo & 46.9 & -96.8 & -4.36 & -0.68 & 5.72 & 3.44 & -6.56 & -1.28 & 7.37 & 4.38 \\
\hline ND & Minot & 48.27 & -101.28 & -4.52 & -1.64 & 3.09 & 3 & -6.89 & -2.19 & 3.21 & 3.78 \\
\hline NE & Grand Island & 40.97 & -98.32 & -6.21 & -0.41 & 2.24 & 3.44 & -7.43 & -0.29 & 3.58 & 4.32 \\
\hline NE & Norfolk & 41.98 & -97.43 & -5.06 & -1.75 & 3.51 & 3.4 & -6.32 & -1.87 & 4.23 & 4.39 \\
\hline NE & North Platte & 41.13 & -100.68 & -4.49 & -0.56 & 1.63 & 2.67 & -5.62 & -1.15 & 1.63 & 3.36 \\
\hline NE & Omaha & 41.37 & -96.52 & -6.87 & 0.82 & 3.86 & 4.64 & -9.06 & 0.62 & 4.74 & 5.87 \\
\hline NE & Scottsbluff & 41.87 & -103.6 & -3.54 & -0.78 & 1.98 & 1.89 & -5.34 & -1.36 & 2.43 & 2.57 \\
\hline NH & Concord & 43.2 & -71.5 & -4.65 & 0.59 & 4.42 & 3.24 & -6.03 & 0 & 4.4 & 3.93 \\
\hline NJ & Atlantic City & 39.45 & -74.57 & -4.44 & -1.05 & 2.74 & 2.82 & -4.68 & -1.47 & 3.19 & 3.38 \\
\hline NJ & Newark & 40.7 & -74.17 & -3.81 & 0.4 & 4.75 & 3.01 & -4.71 & 0.63 & 5.34 & 3.61 \\
\hline NM & Albuquerque & 35.05 & -106.62 & -5.83 & 0.78 & 3.17 & 3.49 & -5.03 & 0.42 & 3.87 & 4.19 \\
\hline NM & Tucumcari & 35.18 & -103.6 & -3.8 & -0.53 & 2.85 & 2.36 & -4.89 & -0.89 & 3.35 & 3.02 \\
\hline NV & Elko & 40.83 & -115.78 & -3.54 & 0.75 & 3.93 & 2.64 & -4.88 & 0.63 & 4.58 & 3.44 \\
\hline NV & Ely & 39.28 & -114.85 & -5.96 & -2.71 & 0.28 & 2.76 & -7.13 & -3.29 & 0.66 & 3.66 \\
\hline NV & Las Vegas & 36.08 & -115.17 & -3.74 & 0.03 & 2.81 & 2.78 & -5.67 & -0.18 & 3.03 & 3.61 \\
\hline NV & Reno & 39.5 & -119.78 & -3.62 & -1.61 & 2.89 & 2.8 & -4.37 & -2.26 & 3.66 & 3.56 \\
\hline NV & Tonopah & 38.07 & -117.13 & -2.8 & 0.3 & 2.73 & 2.5 & -3.58 & 0.64 & 3.54 & 3.26 \\
\hline NV & Winnemucca & 40.9 & -117.8 & -4.44 & 0.32 & 5.01 & 3 & -5.32 & 0.3 & 5.87 & 3.77 \\
\hline NY & Albany & 42.75 & -73.8 & -4.4 & -0.67 & 1.58 & 4.18 & -4.71 & -1.04 & 2.09 & 4.1 \\
\hline NY & Binghamton & 42.22 & -75.98 & -3.73 & -1.15 & 3.09 & 2.42 & -4.65 & -1.29 & 3.64 & 3.06 \\
\hline NY & Buffalo & 42.93 & -78.73 & -4.61 & 0.43 & 6.79 & 3.72 & -5.03 & 1.04 & 8.52 & 4.6 \\
\hline NY & Massena & 44.93 & -74.85 & -2.95 & 0.75 & 3.28 & 2.58 & -3.18 & 0.45 & 4.19 & 3.13 \\
\hline NY & New York City & 40.78 & -73.97 & -4.01 & -0.22 & 3.35 & 2.59 & -4.9 & 0.22 & 5.43 & 3.48 \\
\hline NY & Rochester & 43.12 & -77.67 & -2.97 & -0.76 & 3.16 & 2.57 & -3.37 & -0.61 & 4.93 & 3.29 \\
\hline NY & Syracuse & 43.12 & -76.12 & -4.09 & -1.87 & 1.28 & 2.15 & -5.17 & -2.31 & 2.64 & 2.76 \\
\hline $\mathrm{OH}$ & Akron & 40.92 & -81.43 & -3.75 & -0.82 & 3.13 & 2.69 & -5.26 & -0.9 & 3.54 & 3.37 \\
\hline $\mathrm{OH}$ & Cleveland & 41.4 & -81.85 & -3.07 & -0.3 & 2.31 & 2.41 & -3.88 & -0.44 & 3.3 & 2.96 \\
\hline $\mathrm{OH}$ & Columbus & 40 & -82.88 & -4.2 & 0.03 & 3.56 & 2.94 & -4.88 & -0.62 & 3.75 & 3.57 \\
\hline $\mathrm{OH}$ & Dayton & 39.9 & -84.22 & -4.57 & -0.59 & 3.82 & 3.25 & -5.66 & -0.27 & 5 & 4.03 \\
\hline $\mathrm{OH}$ & Mansfield & 40.82 & -82.52 & -5.18 & -0.15 & 3.79 & 3.35 & -6.05 & -1.04 & 4.91 & 4.27 \\
\hline $\mathrm{OH}$ & Toledo & 41.6 & -83.8 & -4.2 & -1.45 & 3.42 & 2.56 & -4.58 & -1.81 & 4.39 & 3.18 \\
\hline $\mathrm{OH}$ & Youngstown & 41.27 & -80.67 & -3.61 & 0.75 & 5.5 & 3.17 & -4.22 & 0.37 & 6.22 & 3.91 \\
\hline
\end{tabular}

This report is available from the National Renewable Energy Laboratory (NREL) at www.nrel.gov/publications. 


\begin{tabular}{|c|c|c|c|c|c|c|c|c|c|c|c|}
\hline \multirow{2}{*}{ State } & \multirow{2}{*}{ City } & \multirow{2}{*}{ Lat } & \multirow{2}{*}{ Lon } & \multicolumn{4}{|c|}{ Fixed-Tilt Systems } & \multicolumn{4}{|c|}{ One-Axis Tracking } \\
\hline & & & & P90 & P50 & $\mathrm{P} 10$ & STD & P90 & P50 & P10 & STD \\
\hline OK & Oklahoma City & 35.4 & -97.6 & -3.42 & -0.1 & 2.54 & 2.43 & -4.5 & 0.07 & 3.69 & 3.19 \\
\hline OK & Tulsa & 36.2 & -95.9 & -3.31 & -1.5 & 2.37 & 2.57 & -4.45 & -1.6 & 3.57 & 3.2 \\
\hline OR & Astoria & 46.15 & -123.88 & -5.85 & -0.43 & 4.79 & 3.81 & -6.69 & -0.1 & 5.91 & 4.55 \\
\hline OR & Burns & 43.58 & -119.05 & -2.19 & 1.28 & 4.15 & 2.74 & -1.7 & 2.11 & 5.53 & 3.31 \\
\hline OR & Eugene & 44.12 & -123.22 & -6.3 & 0.18 & 5.45 & 4.64 & -7.98 & -0.49 & 6.31 & 5.27 \\
\hline OR & Medford & 42.37 & -122.87 & -4.99 & -1 & 2.08 & 3.18 & -6.69 & -0.61 & 2.97 & 4.1 \\
\hline OR & North Bend & 43.42 & -124.25 & -5.29 & -0.1 & 2.09 & 2.95 & -5.85 & -0.14 & 2.88 & 3.58 \\
\hline OR & Pendleton & 45.68 & -118.85 & -5.39 & -1.17 & 1.59 & 2.71 & -5.87 & -1.3 & 1.9 & 3.43 \\
\hline OR & Portland & 45.6 & -122.6 & -6.3 & -0.57 & 5.33 & 4.36 & -7.27 & -1.51 & 5.36 & 5.18 \\
\hline OR & Redmond & 44.27 & -121.15 & -4.85 & -0.19 & 1.83 & 2.7 & -6.67 & -0.45 & 1.9 & 3.48 \\
\hline OR & Salem & 44.92 & -123.02 & -5.53 & -1.29 & 3.55 & 3.69 & -6.65 & -1.56 & 3.79 & 4.52 \\
\hline PA & Allentown & 40.65 & -75.43 & -5.37 & -0.65 & 2.11 & 2.66 & -6.84 & -1.04 & 1.78 & 3.27 \\
\hline PA & Bradford & 41.8 & -78.63 & -5.6 & -1.18 & 1.96 & 2.91 & -6.91 & -1.29 & 2.21 & 3.52 \\
\hline PA & Erie & 42.08 & -80.18 & -4.43 & -1.81 & 3 & 2.74 & -5.62 & -2.29 & 2.98 & 3.39 \\
\hline PA & Harrisburg & 40.22 & -76.85 & -4.58 & -0.54 & 3.1 & 3.02 & -6.17 & -1.28 & 3.18 & 3.68 \\
\hline PA & Philadelphia & 39.88 & -75.25 & -3.94 & -0.63 & 3.86 & 2.99 & -4.73 & -0.83 & 4.43 & 3.62 \\
\hline PA & Pittsburgh & 40.5 & -80.22 & -3.62 & 0.97 & 3.87 & 2.85 & -3.76 & 0.25 & 4.03 & 3.35 \\
\hline PA & Wilkes-Barre & 41.33 & -75.73 & -2.24 & 0.24 & 2.81 & 2.33 & -3.67 & -0.08 & 3.37 & 2.95 \\
\hline PA & Williamsport & 41.27 & -77.05 & -2.39 & 1.32 & 3.78 & 2.19 & -3.78 & 0.7 & 3.96 & 2.72 \\
\hline RI & Providence & 41.73 & -71.43 & -7.72 & -2.63 & 2.56 & 3.69 & -9.24 & -2.29 & 2.65 & 4.38 \\
\hline sc & Columbia & 33.95 & -81.12 & -3.43 & -0.25 & 3.37 & 2.61 & -4.24 & -0.18 & 3.61 & 3.14 \\
\hline sc & Greenville & 34.9 & -82.22 & -3.83 & -1.37 & 3.09 & 2.75 & -4.35 & -1.66 & 3.96 & 3.32 \\
\hline SD & Huron & 44.38 & -98.22 & -7.05 & -2.83 & 2.14 & 3.54 & -8.84 & -3.59 & 2.92 & 4.6 \\
\hline SD & Pierre & 44.38 & -100.28 & -6.03 & -2.18 & 0.69 & 2.68 & -7.54 & -2.71 & 1.13 & 3.44 \\
\hline SD & Rapid City & 44.05 & -103.07 & -3.72 & -1.05 & 1.4 & 2.1 & -4.44 & -1.34 & 2.08 & 2.78 \\
\hline SD & Sioux Falls & 43.57 & -96.73 & -5.08 & -0.71 & 4.29 & 3.81 & -6.66 & -1.12 & 4.88 & 4.81 \\
\hline TN & Bristol & 36.48 & -82.4 & -2.58 & 0.03 & 5.85 & 3.08 & -2.35 & 0.56 & 7.15 & 3.72 \\
\hline TN & Chattanooga & 35.03 & -85.2 & -3.98 & -1.63 & 3.72 & 3.07 & -5.87 & -1.94 & 4.44 & 4.12 \\
\hline TN & Knoxville & 35.82 & -83.98 & -1.76 & -0.17 & 5.92 & 2.87 & -2.73 & -0.29 & 7.91 & 3.78 \\
\hline TN & Memphis & 35.05 & -89.98 & -6.11 & -2.23 & 0.77 & 2.61 & -7.23 & -2.49 & 1.5 & 3.25 \\
\hline TN & Nashville & 36.12 & -86.68 & -5.09 & -0.72 & 2.99 & 3.44 & -5.77 & -0.78 & 5.04 & 4.43 \\
\hline TX & Abilene & 32.43 & -99.68 & -3.58 & -1.06 & 1.7 & 2.06 & -4.74 & -1.31 & 2.23 & 2.65 \\
\hline TX & Amarillo & 35.23 & -101.7 & -4.12 & -0.81 & 2.02 & 2.31 & -4.93 & -0.81 & 2.65 & 2.94 \\
\hline
\end{tabular}

This report is available from the National Renewable Energy Laboratory (NREL) at www.nrel.gov/publications. 


\begin{tabular}{|c|c|c|c|c|c|c|c|c|c|c|c|}
\hline \multirow{2}{*}{ State } & \multirow{2}{*}{ City } & \multirow{2}{*}{ Lat } & \multirow{2}{*}{ Lon } & \multicolumn{4}{|c|}{ Fixed-Tilt Systems } & \multicolumn{4}{|c|}{ One-Axis Tracking } \\
\hline & & & & P90 & P50 & P10 & STD & P90 & P50 & $\mathrm{P} 10$ & STD \\
\hline TX & Austin & 30.3 & -97.7 & -2.4 & -0.51 & 2.22 & 1.86 & -3.11 & -0.64 & 2.61 & 2.43 \\
\hline TX & Brownsville & 25.9 & -97.43 & -8.3 & 0.87 & 4.06 & 4.52 & -8.37 & 1.29 & 4.37 & 5.25 \\
\hline TX & Corpus Christi & 27.77 & -97.5 & -2.35 & 0.45 & 2.09 & 1.83 & -2.37 & 0.83 & 2.79 & 2.36 \\
\hline TX & El Paso & 31.8 & -106.4 & -4.25 & -0.5 & 2.29 & 2.4 & -4.44 & -0.57 & 2.49 & 2.73 \\
\hline TX & Fort Worth & 32.83 & -97.05 & -2.5 & -0.59 & 2.4 & 1.78 & -2.95 & -0.79 & 3.01 & 2.36 \\
\hline$T X$ & Houston & 29.98 & -95.37 & -3.26 & -0.28 & 2.69 & 2.62 & -3.8 & 0 & 4.03 & 3.16 \\
\hline TX & Lubbock & 33.65 & -101.82 & -3.51 & -0.43 & 2.05 & 2.31 & -4.81 & -0.22 & 2.89 & 3 \\
\hline TX & Lufkin & 31.23 & -94.75 & -2.65 & -0.62 & 1.94 & 1.88 & -2.91 & -0.95 & 2.24 & 2.49 \\
\hline TX & Port Arthur & 29.95 & -94.02 & -4.3 & -1.08 & 1.21 & 2.08 & -5.8 & -1.16 & 2.03 & 2.69 \\
\hline TX & San Angelo & 31.37 & -100.5 & -1.42 & 0.51 & 4.07 & 2.07 & -1.99 & 0.6 & 5.54 & 2.65 \\
\hline TX & San Antonio & 29.53 & -98.47 & -3.81 & 0 & 1.68 & 2.13 & -4.22 & 0.05 & 2.3 & 2.74 \\
\hline TX & Victoria & 28.85 & -96.92 & -4.12 & -1.13 & 1.31 & 1.99 & -3.93 & -1.01 & 2.87 & 2.54 \\
\hline TX & Waco & 31.62 & -97.22 & -3.49 & -0.72 & 2.03 & 2.05 & -3.92 & -0.85 & 2.3 & 2.63 \\
\hline TX & Wichita Falls & 33.97 & -98.48 & -4.74 & -0.86 & 1.62 & 2.4 & -6.31 & -0.91 & 2.09 & 3.14 \\
\hline UT & Cedar City & 37.7 & -113.1 & -4.51 & -1.31 & 2.1 & 3.41 & -6.08 & -2.24 & 2.33 & 4.29 \\
\hline UT & Salt Lake City & 40.77 & -111.97 & -5.37 & -0.65 & 2.39 & 3.74 & -6.01 & -0.91 & 3.13 & 4.64 \\
\hline VA & Norfolk & 36.9 & -76.2 & -4.41 & -1.1 & 1.88 & 2.65 & -5.64 & -1.07 & 2.69 & 3.2 \\
\hline VA & Richmond & 37.5 & -77.33 & -4.1 & -0.54 & 2.67 & 2.73 & -5.51 & -1 & 3.31 & 3.45 \\
\hline VA & Roanoke & 37.32 & -79.97 & -4.1 & -0.48 & 3.27 & 2.6 & -5.38 & -0.61 & 4.49 & 3.23 \\
\hline VA & Sterling & 38.95 & -77.45 & -4.42 & 1.16 & 5.71 & 3.89 & -5.76 & 0.43 & 6.9 & 4.59 \\
\hline VT & Burlington & 44.47 & -73.15 & -4.99 & -0.93 & 3.12 & 3.36 & -5.8 & -0.82 & 4.06 & 3.9 \\
\hline WA & Olympia & 46.97 & -122.9 & -3.89 & 0.11 & 4.64 & 3.69 & -4.16 & 0.27 & 6.11 & 4.57 \\
\hline WA & Quillayute & 47.95 & -124.55 & -4.22 & -1.11 & 6.43 & 3.48 & -4.71 & -1.27 & 8.62 & 4.25 \\
\hline WA & Seattle & 47.45 & -122.3 & -4.57 & 0.16 & 3.37 & 3.4 & -5.84 & -0.27 & 4.89 & 4.63 \\
\hline WA & Spokane & 47.63 & -117.53 & -4.07 & 0.01 & 4.33 & 3.15 & -4.58 & -0.22 & 5.38 & 3.78 \\
\hline WA & Yakima & 46.57 & -120.53 & -3.51 & -0.59 & 2.15 & 2.04 & -4.45 & -0.45 & 2.4 & 2.55 \\
\hline WI & Eau Claire & 44.87 & -91.48 & -4.73 & -0.41 & 3.75 & 3.58 & -5.79 & -0.11 & 5.57 & 4.64 \\
\hline WI & Green Bay & 44.48 & -88.13 & -4.16 & -0.48 & 4.25 & 3.31 & -5.27 & -0.72 & 5.44 & 4.26 \\
\hline WI & Madison & 43.13 & -89.33 & -6.37 & -0.7 & 6.04 & 5.04 & -7.02 & -0.38 & 7.36 & 6.47 \\
\hline WI & Milwaukee & 42.95 & -87.9 & -5.64 & -0.99 & 4.72 & 3.75 & -7.66 & -1.24 & 5.89 & 4.72 \\
\hline WV & Charleston & 38.37 & -81.6 & -3.12 & 0.19 & 6.61 & 4.19 & -4.49 & -0.04 & 8.16 & 5.33 \\
\hline WV & Huntington & 38.37 & -82.55 & -6.37 & -1.44 & 2.65 & 4.9 & -7.47 & -1.96 & 2.65 & 6.15 \\
\hline WY & Casper & 42.92 & -106.47 & -4.42 & -0.96 & 1.4 & 2.52 & -5.2 & -1.27 & 1.72 & 3.35 \\
\hline
\end{tabular}

This report is available from the National Renewable Energy Laboratory (NREL) at www.nrel.gov/publications. 


\begin{tabular}{|c|c|c|c|c|c|c|c|c|c|c|c|}
\hline \multirow{2}{*}{ State } & \multirow{2}{*}{ City } & \multirow{2}{*}{ Lat } & \multirow{2}{*}{ Lon } & \multicolumn{4}{|c|}{ Fixed-Tilt Systems } & \multicolumn{4}{|c|}{ One-Axis Tracking } \\
\hline & & & & P90 & P50 & P10 & STD & P90 & P50 & P10 & STD \\
\hline WY & Cheyenne & 41.15 & -104.82 & -3.82 & -0.44 & 2.14 & 2.05 & -5.09 & -0.6 & 2.84 & 2.72 \\
\hline WY & Lander & 42.82 & -108.73 & -3.91 & -1.57 & 1.98 & 2.44 & -6.18 & -2.19 & 2.4 & 3.31 \\
\hline WY & Rock Springs & 41.6 & -109.07 & -4.36 & -1.04 & 2.04 & 2.59 & -5.17 & -0.84 & 3.12 & 3.45 \\
\hline WY & Sheridan & 44.77 & -106.97 & -3.35 & 0.41 & 2.66 & 2.38 & -5 & 0.16 & 3.23 & 3.15 \\
\hline \multirow{2}{*}{ Terr. } & \multirow{2}{*}{ City } & \multirow{2}{*}{ Lat } & \multirow{2}{*}{ Lon } & \multicolumn{4}{|c|}{ Fixed-Tilt Systems } & \multicolumn{4}{|c|}{ One-Axis Tracking } \\
\hline & & & & P90 & P50 & P10 & STD & P90 & P50 & P10 & STD \\
\hline PI & Guam & 13.55 & 144.83 & -6.37 & -1.62 & 2.57 & 3.52 & -7.99 & -2.48 & 2.58 & 4.42 \\
\hline PR & San Juan & 18.43 & -66 & -2.74 & -0.63 & 2.64 & 2.5 & -3.29 & 0.15 & 3.86 & 3.26 \\
\hline
\end{tabular}

This report is available from the National Renewable Energy Laboratory (NREL) at www.nrel.gov/publications. 